San Jose State University

SJSU ScholarWorks

Master's Theses

Master's Theses and Graduate Research

1999

\title{
LED \& fluorescent light have similar effects on the circadian system of the rat
}

Noam J. Syrkin

San Jose State University

Follow this and additional works at: https://scholarworks.sjsu.edu/etd_theses

\section{Recommended Citation}

Syrkin, Noam J., "LED \& fluorescent light have similar effects on the circadian system of the rat" (1999). Master's Theses. 1848.

DOI: https://doi.org/10.31979/etd.5djb-3n8b

https://scholarworks.sjsu.edu/etd_theses/1848

This Thesis is brought to you for free and open access by the Master's Theses and Graduate Research at SJSU ScholarWorks. It has been accepted for inclusion in Master's Theses by an authorized administrator of SJSU ScholarWorks. For more information, please contact scholarworks@sjsu.edu. 


\section{INFORMATION TO USERS}

This manuscript has been reproduced from the microfilm master. UMI films the text directly from the original or copy submitted. Thus, some thesis and dissertation copies are in typewriter face, while others may be from any type of computer printer.

The quality of this reproduction is dependent upon the quality of the copy submitted. Broken or indistinct print, colored or poor quality illustrations and photographs, print bleedthrough, substandard margins, and improper alignment can adversely affect reproduction.

In the unlikely event that the author did not send UMI a complete manuscript and there are missing pages, these will be noted. Also, if unauthorized copyright material had to be removed, a note will indicate the deletion.

Oversize materials (e.g., maps, drawings, charts) are reproduced by sectioning the original, beginning at the upper left-hand corner and continuing from left to right in equal sections with small overlaps. Each original is also photographed in one exposure and is included in reduced form at the back of the book.

Photographs included in the original manuscript have been reproduced xerographically in this copy. Higher quality $6 " \times$ 9" black and white photographic prints are available for any photographs or illustrations appearing in this copy for an additional charge. Contact UMI directly to order.

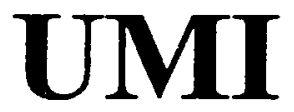

A Bell \& Howell Information Company 300 North Zeeb Road, Ann Arbor MI 48106-1346 USA 


\title{
LED \& FLUORESCENT LIGHT HAVE SIMILAR EFFECTS ON THE CIRCADIAN SYSTEM OF THE RAT.
}

\author{
A Thesis \\ Presented to \\ The Faculty of the Department of Biological Sciences \\ San Jose State University \\ In partial Fulfillment \\ of the Requirements for the Degree \\ Master of Sciences
}

By

Noam J. Syrkin

May 1999 
UMI Number: 1394560

UMI Microform 1394560

Copyright 1999, by UMA Company. All rights reserved.

This microform edition is protected against unauthorized copying under Title 17, United States Code.

\section{UMI}

300 North Zeeb Road

Ann Arbor, MI 48103 
(ㄷ) 1999

Noam J. Syrkin

ALL RIGHTS RESERVED 
APPROVED FOR THE DEPARTMENT OF BIOLOGICAL SCIENCES

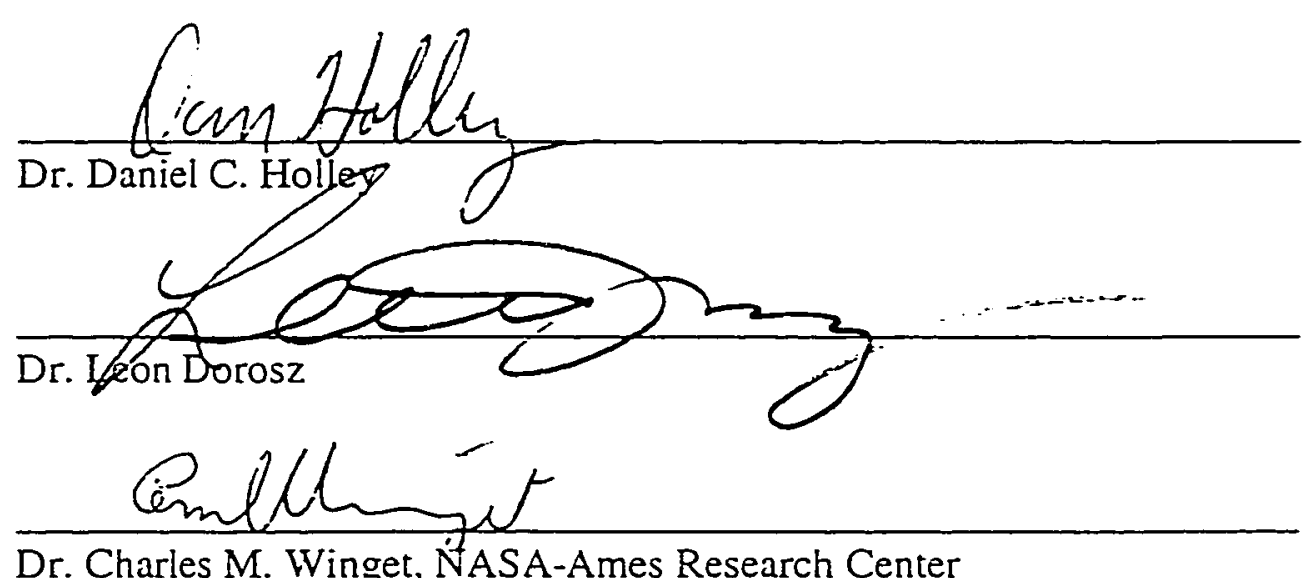

Dr. Charles M. Winglet, NASA-Ames Research Center

APPROVED FOR THE UNIVERSITY

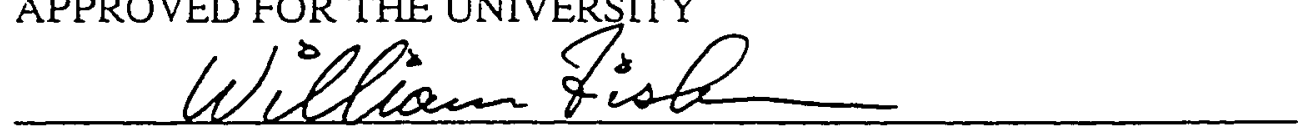




\begin{abstract}
LED \& FLUORESCENT LIGHT HAVE SIMULAR EFFECTS ON THE CIRCADIAN SYSTEM OF THE RAT
\end{abstract}

\title{
By Noam J. Syrkin
}

Currently, the light source most commonly used in animal habitat lighting is CWF light. It was the objective of this study to evaluate a novel LED light source for use in animal habitat lighting by comparing its effectiveness to CWF light in producing and maintaining normal circadian entrainment. The LED and CWF lights had similar spectral power distributions. Sprague-Dawley rats (175-350 g) were kept individually in metabolic cages, under strict lighting control: 4 days of acclimation at 12:12 LD, 14 days of 12:12 LD, 14 days of 24:0 LD (free-run), and finally 14 days of 12:12 LD. Food and water were provided ad libitum. Three behavioral parameters were monitored continuously: gross locomotor activity, drinking, and feeding. Tau increased as a function of light intensity ( $p<0.05$, ANOVA), but there was no difference in tau between rats exposed to constant CWF light vs. rats exposed to constant LED light. This study indicates that LED light can produce the same entrainment pattern as a conventional CWF light at similar intensities $(0.1,1,10,40$, and 80 lux). LED light sources may be suitable replacements for conventional light sources used in animal habitat lighting while providing many mechanical and economical advantages. 


\section{Acknowledgments}

I am sincerely grateful to many people who contributed to the success of this project over the past four years. I wish to express my deepest appreciation to the following individuals for the invaluable assistance with this research: Dr. D.C. Holley, who was the main reason I participated in this project to begin with, for his guidance, sound advice, confidence, and friendship. Mr. G. Mele, for hours of technical assistance in setting up the light sources, debugging the data acquisition software, and statistical analysis. Mr. D. Heeke, for his contribution in running the project and camaraderie. My warmest appreciation is extended to the entire staff of Student Research Assistants - S. Dadras, N.

Mann, S. Ngo, L. Nguyen, E. Parola, B. Quast, P. Sayad, and T. Contreras - who helped with the day to day animal maintenance. And finally, to Dr. C. M. Winget, our NASA Technical Monitor.

Thanks are due to Dr. L. Dorosz from SJSU, and Dr. R. Grindeland, Dr. P. Savage, Dr. C. Wade, Dr. C.W. DeRoshia and Dr. C. M. Winget from NASA for their critical review of the manuscript.

A special gratitude goes to Orit, my wonderful wife, for her understanding, encouragement, and mental support during the long nights of my research and thesis writing.

This research was funded by NASA Cooperative Agreement \# NCC2-779. 


\section{Table of Contents:}

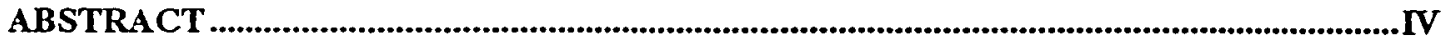

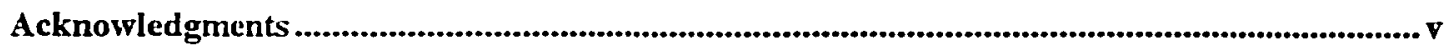

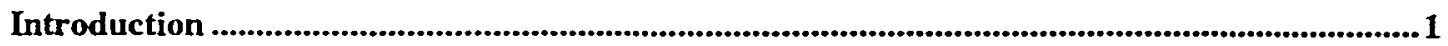

Materials and Methods...................................................................................................................

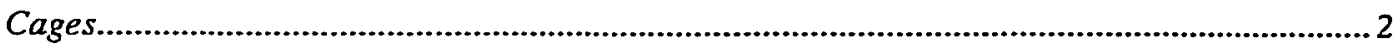

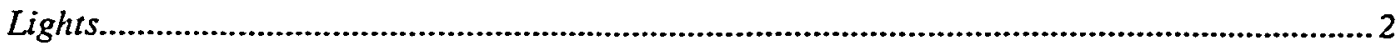

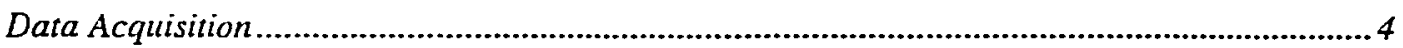

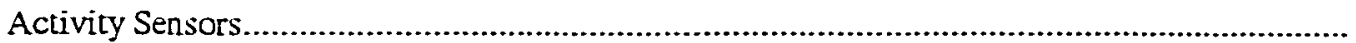

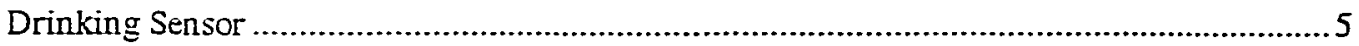

Feeding Sensor

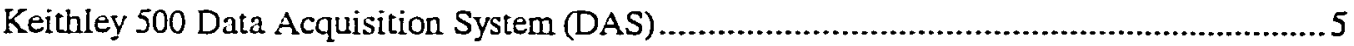

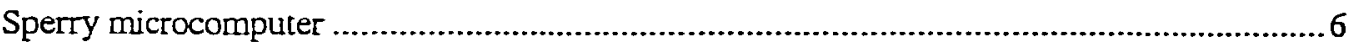

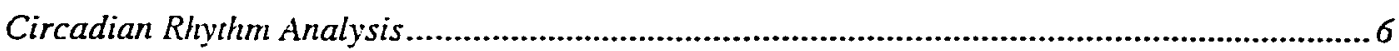

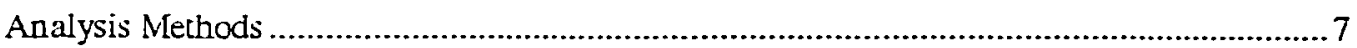

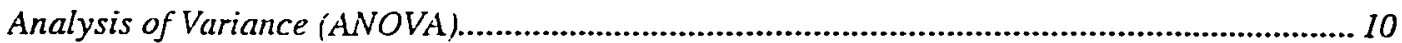

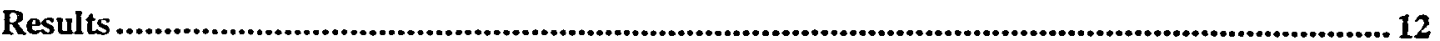

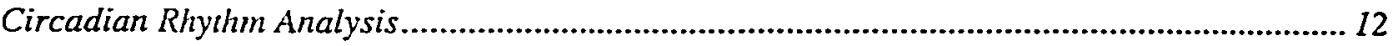

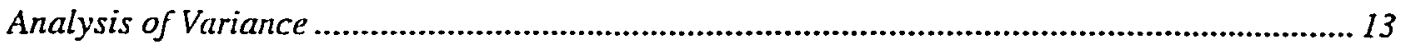

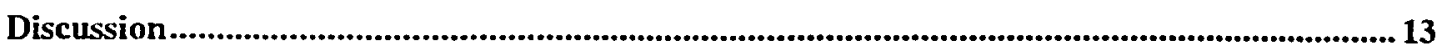

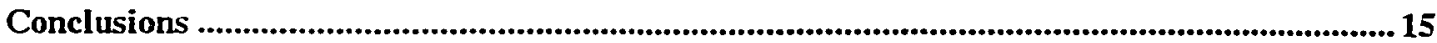

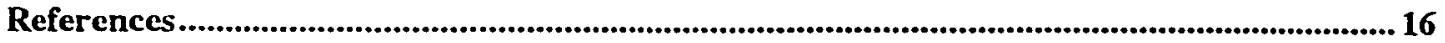




\section{Index of Figures:}

Figure 1. Spectral power distribution curves of LED and CWF light sources used in this study............................18

Figure 2. Experiment 9703LED.1B (0.1 Lux) Rat LMA actogram - LED.......................................................... 19

Figure 3. Experiment 9703LED.1B (0.1 Lux) Rat drinking actogram - LED...................................................... 19

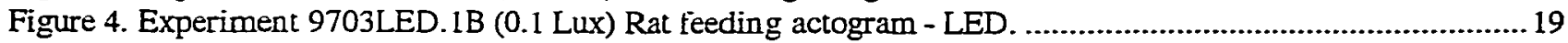

Figure 5. Experiment 9703LED.IB (0.1 Lux) Rat LMA actogram - CWF .........................................................20

Figure 6. Experiment 9703LED.1B (0.1 Lux) Rat drinking actogram - CWF ......................................................20

Figure 7. Experiment 9703LED.1B (0.1 Lux) Rat feeding actogram - CWF ....................................................220

Figure 8. Experiment 9609LED01B (1.0 Lux) Rat LMA actogram - LED .......................................................21

Figure 9. Experiment 9609LED01B (1.0 Lux) Rat drinking actogram - LED....................................................21

Figure 10. Experiment 9609LED01B (1.0 Lux) Rat feeding actogram - LED .....................................................2 21

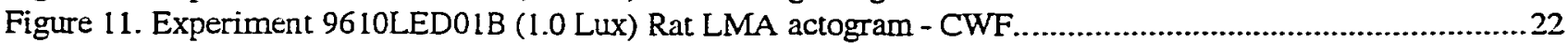

Figure 12. Experiment 9610LED0IB (1.0 Lux) Rat drinking actogram - CWF...........................................22

Figure 13. Experiment 9610LED01B (1.0 Lux) Rat feeding actogram - CWF.......................................................22

Figure 14. Experiment 9510LED10 (10 Lux) Rat LMA actogram - LED......................................................23

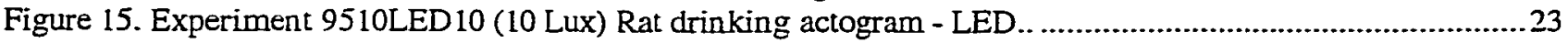

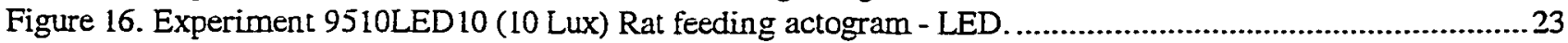

Figure 17. Experiment 9601LED10 (10 Lux) Rat LMA actogram - CWF......................................................24

Figure 18. Experiment 9601LED10 (10 Lux) Rat drinking actogram - CWF....................................................24

Figure 19. Experiment 9601LED10 (10 Lux) Rat feeding actogram - CWF. ...................................................24

Figure 20. Experiment 9605LED40 (40 Lux) Rat LMA actogram - LED ....................................................25

Figure 21. Experiment 9605LED40 (40 Lux) Rat drinking actogram - LED .................................................25

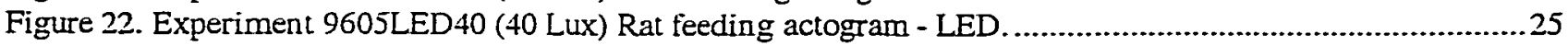

Figure 23. Experiment 9605LED40 (40 Lux) Rat LMA actogram - CWF...................................................26

Figure 24. Experiment 9605LED40 (40 Lux) Rat drinking actogram - CWF....................................................26

Figure 25. Experiment 9605LED40 (40 Lux) Rat feeding actogram - CWF.................................................26

Figure 26. Experiment 9705LED100B (80 Lux) Rat LMA actogram - LED .....................................................27

Figure 27. Experiment 9705LED 100B (80 Lux) Rat drinking actogram - LED.....................................................27

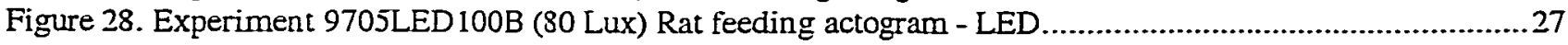

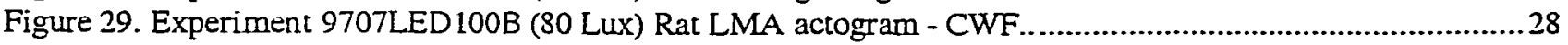

Figure 30. Experiment 9707LED 100B (80 Lux) Rat drinking actogram - CWF............................................28

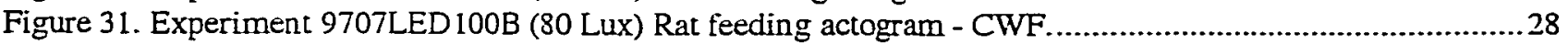

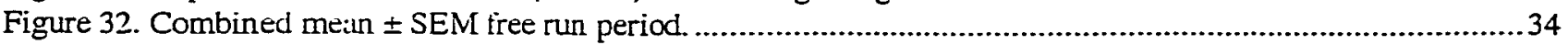

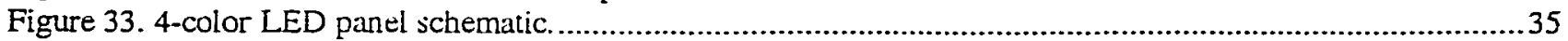

\section{Index of Tables:}

Table 1. Time Series Analysis Sequence Used for Activity, Feeding, and Drinking Data ....................................9

Table 2. Free run periods (tau, hours) for rats kept under constant illumination from cool white fluorescent or RYGB LED panels listed in chronological order.

Table 3. Individual tree run periods (tau, hours) for rats kept under constant illumination from cool white

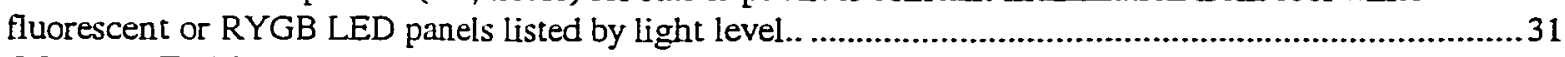

Table 4. Mean \pm SEM free run period (tau, hours) of individual variables. .......................................................32

Table 5. Mean \pm SEM tree run period (tau, hours) of combined variables. . ...................................................33

Table 6. ANOVA table for the analysis of combined free run periods..................................................................3

Table 7. Planned comparisons among light levels. 


\section{Introduction}

Needing precise engineering specifications for construction of lighting systems for animal cages to be used in microgravity experiments, in 1988 the National Aeronautics and Space Administration (NASA) convened a working group to address this issue and to publish standards (1). At that time, federal guidelines provided little detail on animal habitat lighting requirements (2). Though the latest version of the federal Guide for the Care and Use of Laboratory Animals indicates that intensity and duration of light exposure are important factors for animal holding room lighting, it still does not specify standards for photoperiod or wavelength (3).

Previous space shuttle animal cages (Animal Enclosure Module, Research Animal Holding Facility) have been illuminated by incandescent lights (4) which do not provide optimal spectral characteristics (1) and produce considerable heat. For these reasons, combined with the fact that most ground animal vivariums are illuminated by cool white fluorescent lights (CWF), NASA is interested in alternate lighting technologies. Light emitting diodes (LED) have been proposed as a candidate lighting alternative. LED systems are inexpensive, and offer inherent advantages including: spectral control, high efficiency, long operating life, relatively low heat production, ruggedness (solid state), and certain mechanical/size advantages (5).

The purpose of this study was to evaluate the effectiveness of LED arrays (of similar spectral characteristics) compared to CWF lighting in maintaining photo entrainment of several selected behavioral circadian rhythms in rats: gross locomotor activity, feeding, 
and drinking. These parameters were evaluated at five light intensities $(0.1,1.0,10,40$, and 80 lux).

\section{Materials and Methods}

We exposed 175-350g male Sprague-Dawley albino rats (Simonsen Laboratories, Gilroy, CA) to light from CWF bulbs or from four-color (red, green, blue, and, yellow) LED arrays at five light intensities (0.1, 1.0, 10, 40, 80 lux).

\section{Cages}

Rats were housed individually in Nalgene metabolism cages made of lexan and polymethyl carbonate (Nalge Co., Rochester NY). These materials pass most wavelengths of light in the visible spectrum, and a portion of ultraviolet. The metabolism cages were placed inside separate ventilated, radio frequency shielded, light- tight wooden cabinets (I.D. $66 \mathrm{~cm} \times 66 \mathrm{~cm} \times 76 \mathrm{~cm}$ ). These cabinets were contained in a sound-attenuated, environmental chamber at constant temperature $\left(20-22 \mathrm{C}^{\circ}\right)$. Relative humidity was between 40 and $60 \%$.

Food (Purina 5001 Rodent Chow, Ralston Purina, St. Louis, MO) and distilled water were provided ad libitum.

\section{$\underline{\text { Lights }}$}

Each cabinet contained either a CWF lamp (GE Cool White, F14T12 CW, 14 Watt) or a four-color (red, green, blue, yellow) LED array (Figure 33). Light sources were positioned directly above each cage approximately 8 inches from the cage floor. 
Illuminance from the CWF lamps and the LED arrays were set to $0.1,1,10,40$, or 80 lux at animal head height using a calibrated radiometer (Model IL-1700, International Light Inc., Newburyport, MA) and a photometer sensor (Model \#SED038, Y filter and W diffuser). Total irradiance provided by the LED arrays and the CWF lights were measured directly using a calibrated irradiance sensor (Model \# SED 038, F filter and W diffuser). The irradiance measures $\left(\mu \mathrm{W} / \mathrm{cm}^{2}\right)$ corresponding to the illuminance settings were: 80 lux: LED 22.4, CWF 25.6; 40 lux: LED 11.2, CWF 13.11; 10 lux: LED 2.8, CWF 3.2; 1.0 lux: LED 0.28, CWF 0.32; 0.1 lux: LED 0.03, CWF 0.04.

The LED array spectrum could not be adjusted to exactly match that of the CWF lamps. We, therefore, set the irradiance of each LED color to match that part of the CWF spectrum where most of the energy was contributed by that color LED. Irradiance levels of each LED color were adjusted to be equal to the corresponding color band irradiances of the CWF lamps. The measured spectrum (300nm - 800nm) was divided into threecolor bands. Each band covered sections of the spectrum where most of the energy was contributed by one or two LED colors. The blue LED band spanned 300 to $535 \mathrm{~nm}$ The green and yellow LED band spanned 540 to $620 \mathrm{~nm}$. The red LED band spanned 625 to $800 \mathrm{~nm}$ Energy distribution for the LED array was blue $35.8 \%$, green and yellow $47.2 \%$, and red $17 \%$. Energy distribution for the CWF bulb was blue $34.6 \%$, green and yellow $48.6 \%$, and red $16.8 \%$. For the spectral power distribution curves see Figure 1.

The light schedules for all experiments were similar. An initial approximate three week period of 12:12 LD (LD1) was followed by a 14 day period of 24:0 LL (constant 
light, $\mathrm{LL})$, then by another 14 day period of 12:12 LD (LD2). Light intensities were set at the beginning of an experiment and remained unchanged for the duration. Lights came on at 0700 and remained on until 1900, except during the 24:0 LL segment, when lights were on constantly.

\section{Data Acquisition}

The continuously monitored dependent variables were gross locomotor activity (LMA), feeding time, and drinking time. All parameters were recorded automatically every minute. Data are presented in double raster plots (Figures 2-31). These actograms are continuous records of activity over the course of the experiment. They are double plotted so that the pattern of the circadian rhythm can be seen easily with the unaided eye. In an entrained animal, each day's activity is aligned with a specific onset and offset. During the so-called "free-running" time, the animal is exposed to constant environmental conditions (i.e., constant light, 24:0 LL). In LL, each day's activity will drift a little with the "intrinsic" rhythm of the internal biological clock (9). The appearance of a drift is a means of indicating whether or not the animal was previously entrained to the light cycle (an exogenous stimulus).

\section{Activity Sensors}

Each metabolism cage was attached to a particleboard base which floated above the cabinet floor on four steel springs. Rat locomotion or grooming caused the cage to move. A three-axis ballistocardiograph accelerometer attached to the top of the metabolism cage frame converted cage movements into a voltage change. The ballistocardiograph 
preamplifier and main amplifier multiplied, filtered, and twice integrated the accelerometer voltage. The amplifier output voltage was approximately proportional to the distance moved by the rat in a few seconds.

\section{Drinking Sensor}

Rat drinking water came from a 100 -ml plastic bottle equipped with a metal spout with an internal ball bearing to prevent drips. Rats standing on the metal cage floor grid licked the spout to obtain water. A custom designed circuit sensed the microampere currents that flowed from the metal waterspout through the rats body to the metal floor grid. The output of this circuit indicated whether the rat was or was not touching the drinking spout.

\section{Feeding Sensor}

A small drawer contained a reservoir of food (Purina 5001 Rodent Chow) which was available to the rat through a small opening off a short tunnel attached to the metabolism cage. An Omnitech sensor (Model \#FM8, Omnitech Electronics, Inc., Columbus, $\mathrm{OH}$ ) utilizing an infrared LED/ photodiode pair surrounded the food drawer opening. A rat reaching into the food reservoir interrupted the infrared beam. The Omnitech monitor converted the beam interruption into a TTL compatible pulse. When the rat interrupted the beam, the monitoring system recorded duration of feeding activity.

\section{Keithley 500 Data Acquisition System (DAS)}

Two (one per 6 cages) Series 500 DAS (Keithley Metrabyte, Taunton, MA) converted activity, drinking, and feeding signals into a form which could be passed on to 
the data acquisition program running on the Sperry microcomputers. Each DAS total sample rate was 100 samples per second. As there were 3 channels per cage and 6 cages, each channel was sampled at $100 / 18(-5.5)$ samples per second. This produced approximately 300 samples per channel per minute.

\section{Sperry microcomputer}

Each Sperry microcomputer (MS-DOS) ran the Data Acquisition Program, which transferred data from the DAS, accumulated data for 1 minute, and then recorded the data on floppy disks. Data were recorded at the rate of one datum per minute. Each datum is the sum of many samples read from the Keithley DAS. The number of summed samples varied from one datum to the next. This number, $\mathrm{N}$, was recorded with each datum.

Activity data values represented the total amount of physical activity in the preceding minute. This combined intensity and duration information. Feeding and drinking values represent the relative amount of time spent in these activities. Data were printed (hard copy) and stored on floppy disks.

\section{Circadian Rhvthm Analvsis}

Time series analysis consisted of several filtering steps followed by period analysis. 


\section{Analysis Methods}

\section{Blocked Sensor edit}

Occasionally food pellets in the food reservoir stacked up and interrupted the infrared beam This created invalid data values. The blocked sensor edit removed values that were at least $90 \%$ of the number of samples used to create the value.

\section{Missing edit}

Data values were not recorded for every time interval, e.g., several were lost during routine maintenance when the data diskette was changed, and occasionally the computer stopped recording due to software problems, printer paper feed problem, or power failures. The missing edit routine replaced each missing value with an estimated value. Each estimated value was the mean of four adjacent values. Two adjacent values were defined as being 24 hours before the missing value, and the other two adjacent values were defined as being 24 hours after the missing value.

\section{Decimate}

This procedure added successive data values to create a new value. $N$ was the number of summed samples. This reduced the number of samples and provided a smoothing function. 


\section{Binary conversion}

This counted the number of nonzero data values in a given number of values. $\mathrm{N}$ is the number of values checked for nonzero values.

\section{Robust Locally Weighted Regression (RLWR)}

This filtering technique used a fixed number of adjacent values to predict what the central value should be in order to create a smooth curve. This routine produced one of two data sets as its output. The first result smoothed the data and allowed RLWR to act as a low pass filter. The second result, the residual (difference between the smoothed data and the original data), allowed RLWR to act as a high pass filter.

\section{Fourier analysis}

This applied the discrete Fourier transform to calculate the spectral composition of the last 10 days of data values for the periods LD1, LL, and LD2. The largest spectrum amplitude value occurred at the dominant frequency. This was converted into a period and reported as the free running period, tau. 
Table 1. Time Series Analysis Sequence Used for Activity, Feeding, and Drinking Data Analysis of activity data used the following steps:

1) Missing edit

2) Decimate with $n=5$

3) $R L W R$ with $n=36$ saving the smoothed curve

4) Decimate with $n=4$

5) RLWR with $n=144$ saving the residual

6) Fourier analysis

Analysis of feeding data used the following steps:

1) Blocked sensor edit

2) Missing edit

3) Binary conversion $(n=20)$

4) $R L W R$ with $n=9$ saving the smoothed curve

5) RLWR with $n=144$ saving the residual

6) Fourier Analysis

Analysis of drinking data used the following steps:

1) Missing edit

2) Binary conversion $(n=20)$

3) RLWR with $n=9$ saving the smoothed curve

4) $R L W R$ with $n=144$ saving the residual

5) Fourier Analysis 


\section{Analvsis of Variance (ANOVA)}

Free running periods arrived at using the techniques above, were tested for effects due to the type of light, light intensity, and variation among rats, using analysis of variance techniques. The design used was a two-level nested ANOVA within a two-way factorial ANOVA (10). The factorial ANOVA portion tested for effects due to light intensity and light type. The nested analysis portion tested for the effect of variation among rats within the subgroups.

The factorial ANOVA design tested for significant effects due to light type, light intensity, or the interaction of these two. Several changes in the standard factorial ANOVA design were required to fit the pattern of the time series analysis results. Failure of equipment resulted in an unequal number of taus in the subgroups. These variations of $\mathrm{N}$ depended mostly on the random nature of computer failures and appeared to be independent of the type or intensity of light used. These assumptions allowed the use of unweighted means analysis methods (11) which estimated the partitioning of variation within the ANOVA.

Another addition to the factorial ANOVA design was the nested nature of data within the subgroups. Within each subgroup, there was random genetic variation among the rats of the subgroup. For each rat, there was random variation among the three estimates of tau. Factorial methods cannot be used here because the three-tau values are not independent of one another. Nested methods structure the analysis into levels to account for variation contributed by the random differences between rats and between tau 
estimates. This structure reduces the error term used for significance testing in the factorial portion of the ANOVA.

Nested analysis tested for significant variation among rats within each subgroup. Variation at this level would mean that individual rats responded differently to the same experimental conditions. Each subgroup contained the feeding, drinking, and activity taus for all rats tested at the same light intensity using the same light type. Combining the three taus for each rat was allowed by assuming that the tau values were not independent of one another and that any differences were due to random variation among parameters. This requires that the same "clock" control feeding, drinking, and activity (9). Previous findings in our laboratory support this notion $(12,13)$ 


\section{Results}

Time series analysis (Table 1) and ANOVA (Table 6) show a significant effect on the animals' periods $(\mathrm{p}<0.05)$ due to light intensity, but no difference in the free running periods of the animals due to the different light source (i.e. CWF vs. LED) within a light intensity subgroup (0.1 to 80 lux).

\section{Circadian Rhvthm Analvsis}

Visual inspection of the actograms or raster plots (Figures 2 - 31) clearly indicated that circadian rhythmicity was maintained in all parameters monitored. While in LD 1 and LD2, the rats' rhythmicity was synchronized to the external lighting cue, whereas in LL it started drifting based on the animals' internal clock timing. Captions for each plot indicate experiment name, light intensity, and whether the rat was exposed to LED or CWF lights.

Table 2 lists individual free run periods in chronological order. Table 3 shows the same values listed by light intensity, parameter measured and light type. There were three measured parameters - activity, drinking, and feeding, and five levels of light intensity.

Table 4 shows the mean free run periods listed by light intensity, parameter measured, light type, and total rat subjects $(\mathrm{N}$ ) for a given intensity. Table 3 indicates that tau values for the three parameters within the five intensities are similar. Table 5 and Figure 32 show the mean periods \pm SEM for combined activity, drinking, and feeding free run periods (tau) listed by light intensity and light type. These were the subgroup values used in the combined ANOVA. 


\section{Analysis of Variance}

Table 6 shows the results of the analysis of variance. The factorial portion of the ANOVA found a significant effect $(p<0.05)$ due to the intensity of light. This was expected since the free running period increases with light intensity (6). The nested analysis found a significant $(\mathrm{p}<0.05)$ amount of variation due to differences among rats within each subgroup.

\section{Discussion}

Light Emitting Diodes (LED) are small, low power, semiconductor (solid-state) devices that emit red, green, yellow, blue, or various other wavelengths of light. They operate on DC voltages in the range of 1.5 to 3.0 volts. LEDs are more efficient in the conversion of electric current to light radiation than are comparable fluorescent or gas discharge lamps (15). They can be manufactured to emit a specific wavelength of light and can be assembled to emit optimal spectral profiles needed for maximally efficient photosynthesis, or other physiological needs. In some applications, at a $100 \%$ duty cycle they can be expected to last for up to 75 years! (15). A fluorescent or gas discharge lamp may have to be replaced in less than two years. LEDs provide a low cost, durable, rugged, and reliable lighting source. They draw relatively little power with low heat production. LED lights are becoming more abundant in our environment. They are used in traffic stoplights, car taillights and instrumentation panels, remote controls, computers, toys, and many other applications. 
Gross locomotor activity, drinking and feeding were chosen as our behavioral dependent variables since they are relatively easy to monitor, and, they reflect the internal underlying circadian oscillator in the rat. Tischler et al. $(6,7)$ found that rat circadian entrainment was maintained using light intensities as low as 0.1 lux. Forty-lux was included since this was the average light intensity recommendation made to NASA in 1988 by the science working group (1). Recent work done in our laboratory (8) had confirmed that 40 lux is preferable to higher illumination since it produces normal circadian entrainment, nornal reproductive activity, and does not cause retinal damage (14). Eighty-lux was near the upper limit of light intensity achievable by the LED arrays in our experimental caging configuration.

It should be noted that activity was recorded in five of the 12 cages used for this study. All cages in environmental chamber A lacked activity monitors, as well as cage six in environmental chamber B. The accelerometers were of an older model, which could not be repaired, and funds were not available to acquire 12 new devices. Reasons for missing data or inability to determine tau values (other than random computer failure, as mentioned above) included either: a temporary short circuit; a disconnected cable to a drinking monitor; or an over-filled food drawer which blocked the infrared beam, resulting in the recording of erroneous data.

Combined mean free run periods (Table 5) varied from $24.6 \pm 0.1 \mathrm{hrs}$. at 0.1 lux to $25.9 \pm 0.1 \mathrm{hrs}$. at 80 lux for CWF and from $24.7 \pm 0.2 \mathrm{hrs}$. at 0.1 lux to $25.9 \pm 0.1 \mathrm{hrs}$. at 80 lux for LED lights (mean \pm SEM). The free run period increased with increasing light 
intensity, except for both light types at 10 lux (Figure 32). This result is consistent with Aschoff's rule that in nocturnal rodents in constant light, free run period increases with the light intensity.

\section{Conclusions}

This study shows that a novel LED light source can maintain circadian rhythm entrainment in rats as well as a conventional CWF light source at similar light intensities ( 0.1 to 80 lux). We have demonstrated that there are no significant differences between rats exposed to either light source in three measured behavioral activities. Time series analysis and ANOVA found a significant effect on period $(\mathrm{p}<0.05)$ due to light intensity, but no difference in the free running period of rats exposed to constant CWF light and rats exposed to constant LED light within a light intensity subgroup. In addition, our parallel study (14) showed LED lights to suppress pineal gland melatonin concentrations equivalently to the CWF light source, while producing no difference in retinal function or structure. LED light sources may be suitable replacements for conventional light sources used in animal habitat lighting while providing many mechanical and economical advantages. 


\section{References}

1. Holley, D.C., C.M. Winget and H.A. Leon. 1988. Lighting requirements in microgravity - rodents and non-human primates. NASA Technical Memorandum \#101077, 273pp.

2. National Research Council. 1985. Guide for the Care and Use of Laboratory Animals. National Institutes of Health Publication No. 85-23, 83pp.

3. National Research Council. 1996. Guide for the Care and Use of Laboratory Animals. National Academy Press. Washington, D.C., 125pp.

4. Lockheed Engineering \& Science Company. 1993. Animal Enclosure Module (AEM) crew training familiarization manual. NASA-Ames Research Center, CA.

5. Drysdale, A. and J. Sager. 1996. A Re-evaluation of Plant Lighting for a Bioregenerative Life Support System on the Moon. $26^{\text {th }}$ International Conference on Environmental Systems. Society of Automotive Engineers Technical Paper \#961557.

6. Tischler, A.C., C.M. Winget, D.C. Holley, C.W. DeRoshia, J. Gott, G. Mele, and P.X. Callahan. 1992. New findings regarding light intensity and its effects as a Zeitgeber in the Sprague-Dawley rat. The Physiologist 36 (1, Suppl.): S125-S126.

7. Tischler, A.C., D.C. Holley, C.W. DeRoshia, J. Gott, S. Okumura, G. Mele C.M. Winget, and P.X. Callahan. 1993. Circadian entrainment of male Sprague-Dawley rats using low light intensity. The FASEB Journal 6(5): A1832.

8. Holley, D.C., 1994. Final report for NASA COOPERATTVE AGREEMENT \# NCC2-593.

9. Moore-Ede, M.C., F.M. Sulzman and C.A. Fuller. 1982. The clocks that time us: The circadian timing system in mammals. Harvard Univ. Press, Cambridge. 448 pp.

10. Sokal, R.R. and F.J. Rohlf. 1981. Biometry, second edition. W. H. Freeman and Company, New York, 859pp.

11. Winer, B.J., D.R., Brown, and K.M. Michels. 1991. Statistical Principles in Experimental Design, third edition. McGraw-Hill, Inc, New York.

12. Edgar, D.M., D.C. Holley, N.L. Kerst, C.W. DeRoshia, and C.M. Winget. 1981. Simultaneous measurement of multiple circadian physiological parameters from individual rats. The Physiologist 24: 69

13. Edgar, D.M., D.C. Holley, N.L. Kerst, C.W. DeRoshia, and C.M. Winget. 1982. Circadian rhythm phase dissociation following light-dark cycle inversion in the rat. Fed. Proc. 41: 1697

14. Heeke, D.S., M.P. White, G.D. Mele, J.P. Hanifin, G.C. Brainard, M.D. Rollag, C.M. Winget, and D.C. Holley. 1999. Light-emitting diodes and cool white fluorescent light similarly suppress pineal gland melatonin and maintain retinal function and morphology in the rat. Laboratory Animal Science (in press, 1999). 
15. Troubled Times web site - http://www.zetatalk3.com/thub.htm, 2/17/1999, 19:30hrs. 

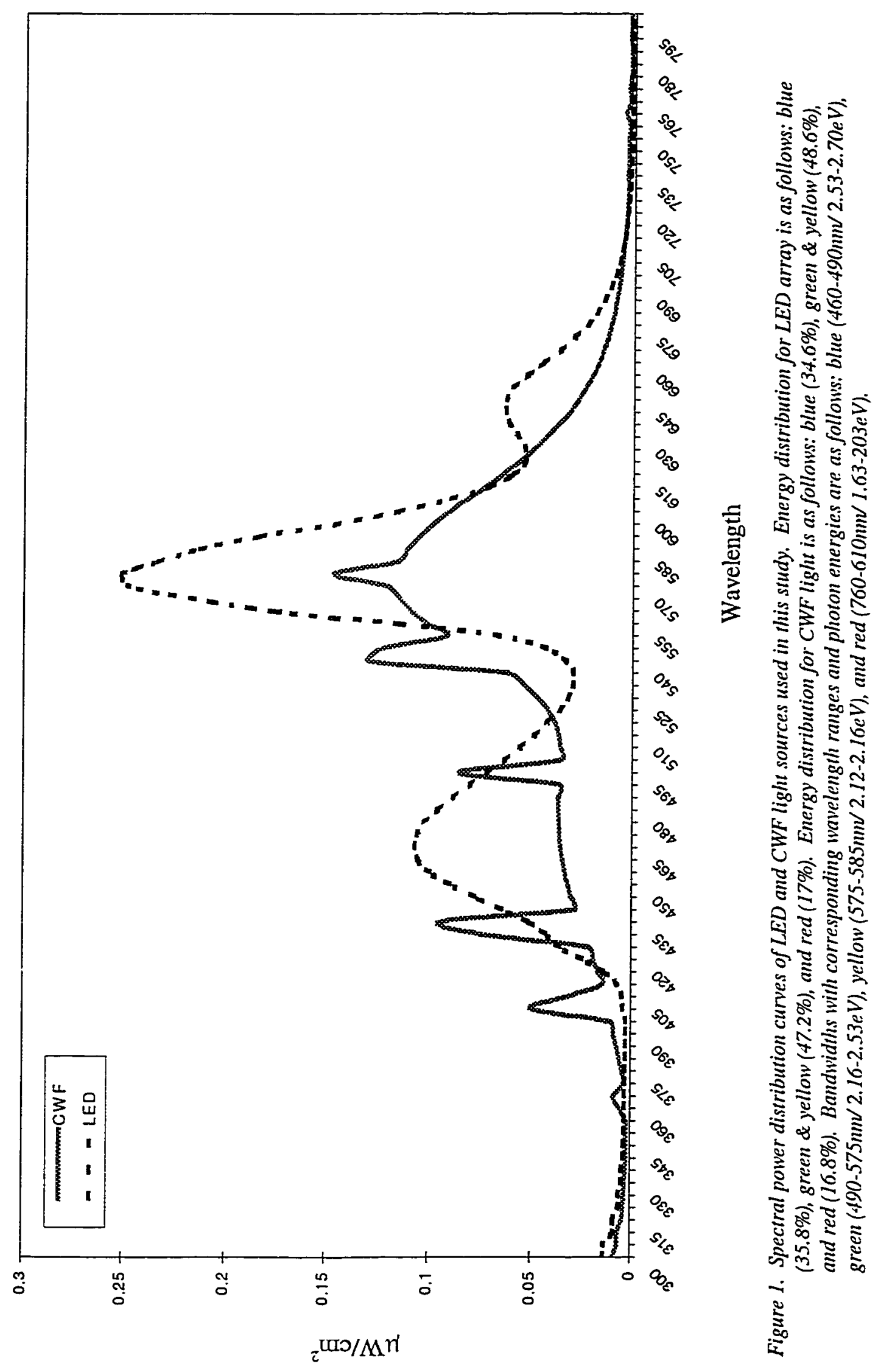
Figure 2. Experiment 9703LED.1B (0.1 Lux) Rat LMA actogram - LED. All values above the median are plotted. Twenty Four hour epochs are double plotted. 0700

700

12L:12D

$24 L: O D$

$12 L: 12 D$

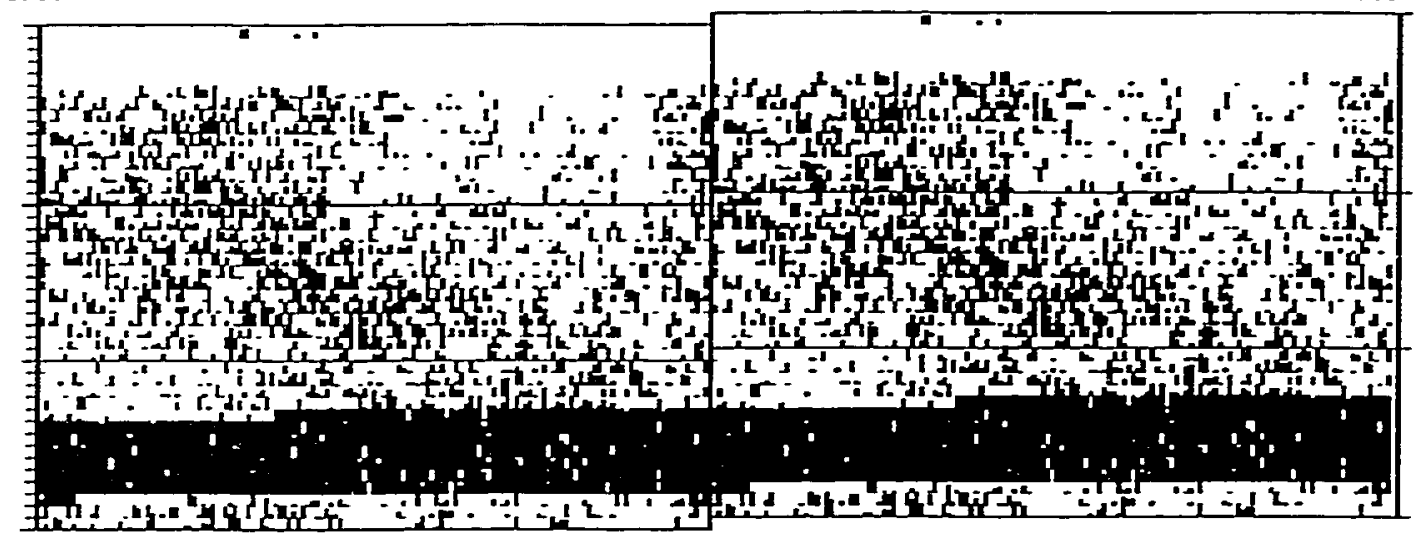

Figure 3. Experiment 9703LED.IB (0.I Lux) Rat drinking actogram - LED. All non-zero values are plotted. Twenty Four hour epochs are double plotted.

0700

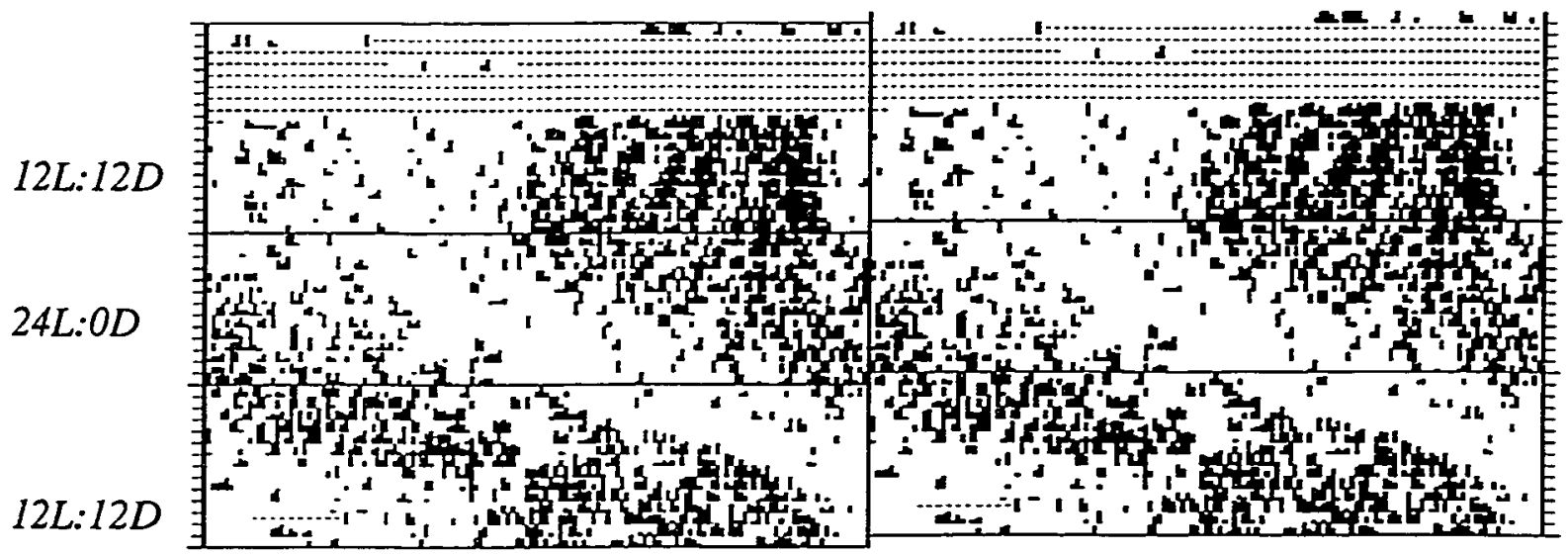

Figure 4. Experiment $9703 L E D .1 B(0.1$ Lux) Rat feeding actogram - LED. All non-zero values are plotted. Twenty Four hour epochs are double plotted.

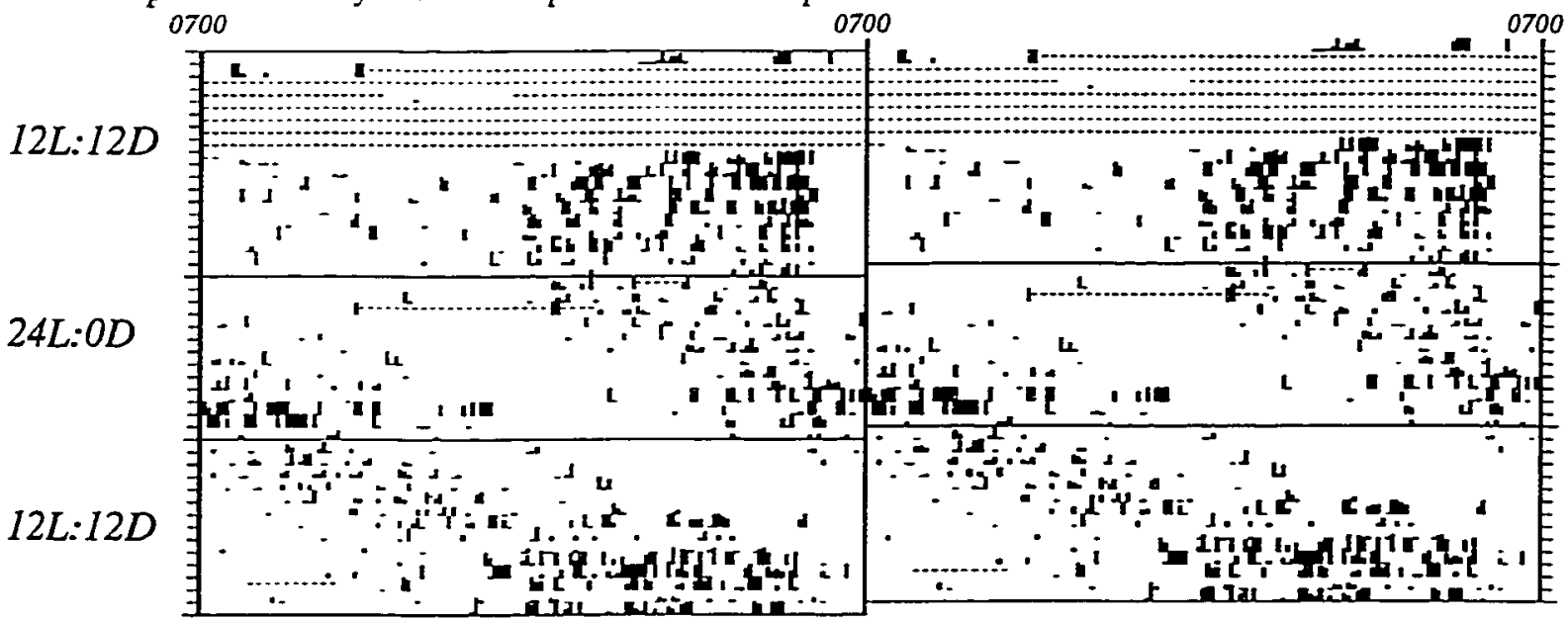


Figure 5. Experiment 9703LED.1B (0.1 Lux) Rat LMA actogram-CWF. All values above the median are plotted. Twenty Four hour epochs are double plotted.

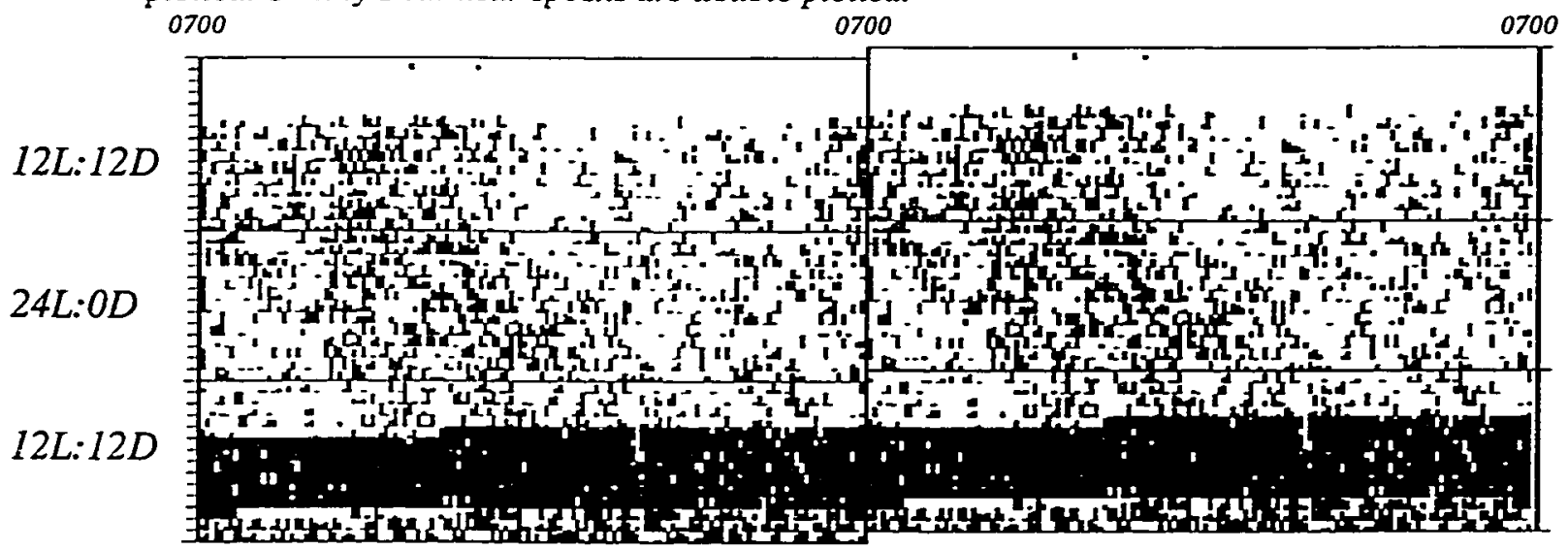

Figure 6. Experiment 9703LED.1B (0.1 Lux) Rat drinking actogram-CWF. All non-zero values are plotted. Twenty Four hour epochs are double plotted. 0700

0700

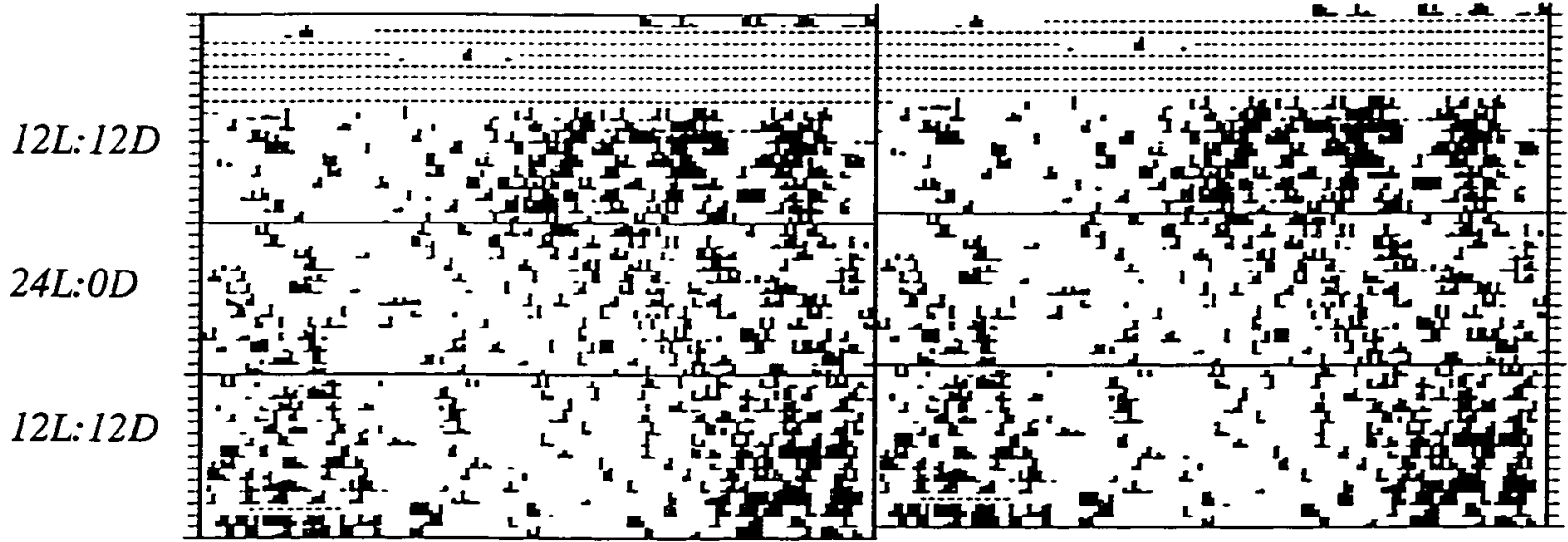

Figure 7. Experiment 9703LED.1B (0.1 Lux) Rat feeding actogram-CWF. All non-zero values are plotted. Twenty Four hour epochs are double plotted.

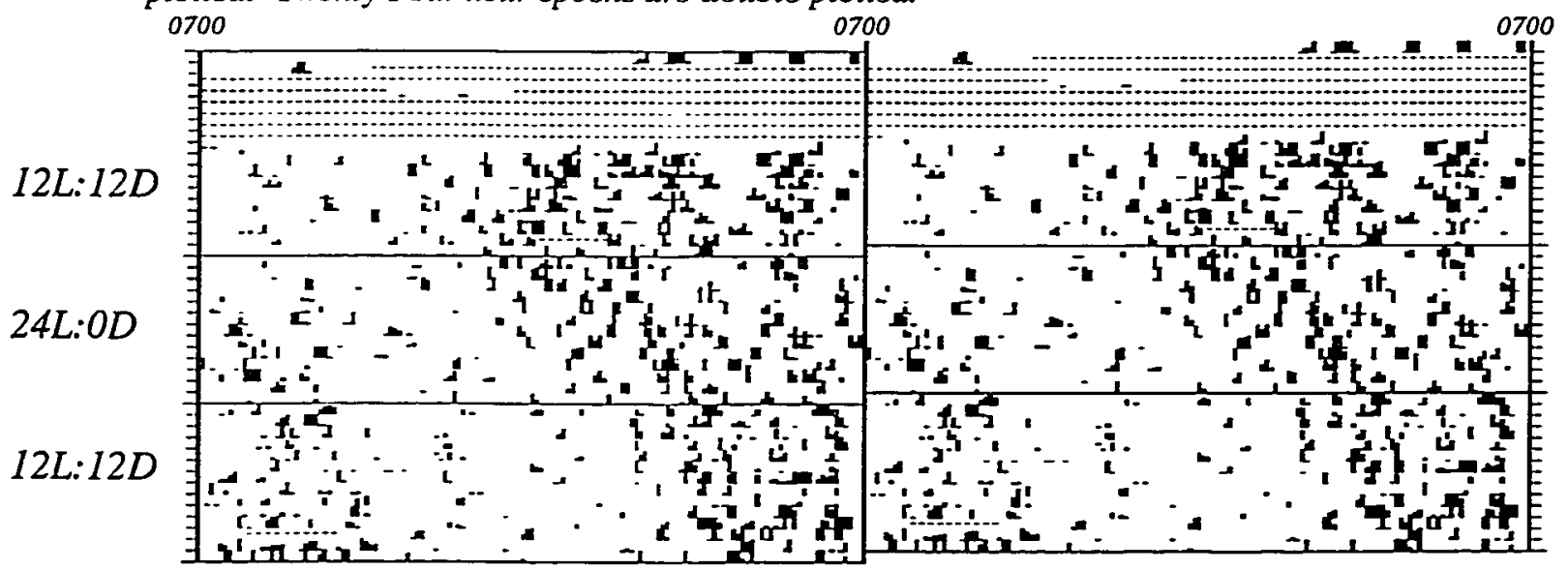


Figure 8. Experiment 9609LEDO1B (1.0 Lux) Rat LMA actogram - LED. All values above the median are plotted. Twenty Four hour epochs are double plotted. 0700

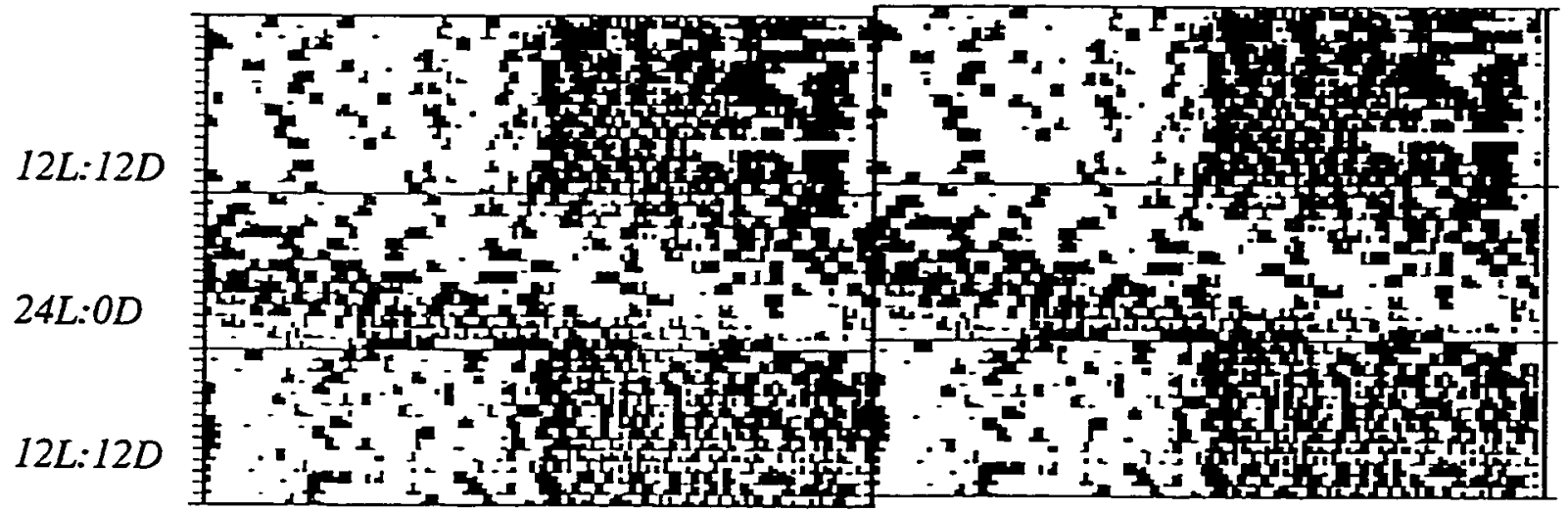

Figure 9. Experiment 9609LEDO1B (1.0 Liax) Rat drinking actogram - LED. All non-zero values are plotted. Twenty Four hour epochs are double plotted. 0700 0700

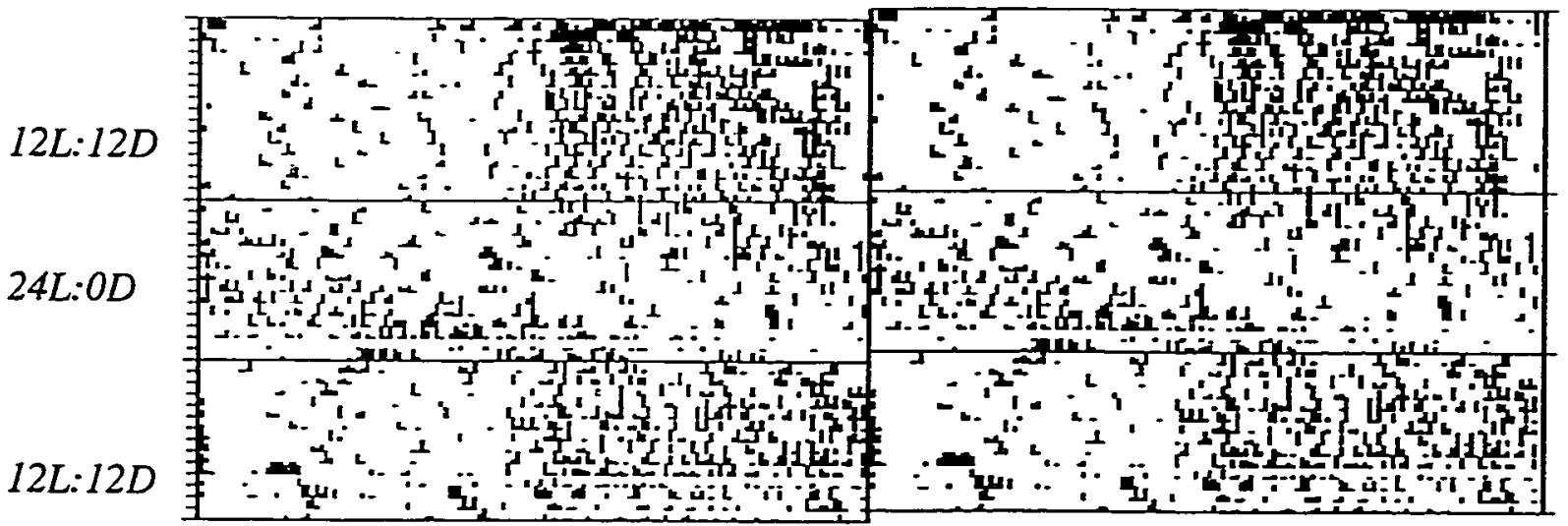

Figure 10. Experiment 9609LEDO1B (1.0 Lux) Rat feeding actogram - LED. All non-zero values are plotted. Twenty Four hour epochs are double plotted.

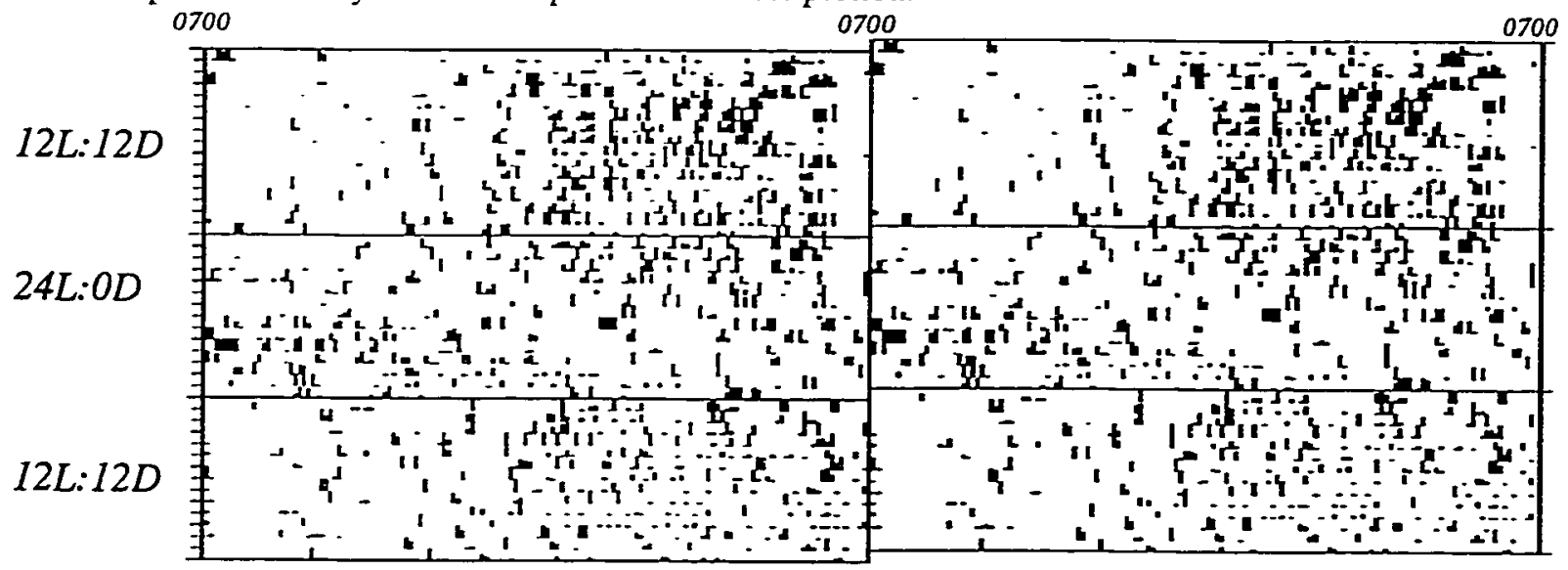


Figure 11. Experiment 9610LED01B (1.0 Lux) Rat LMA actogram-CWF. All values above the median are plotted. Twenty Four hour epochs are double plotted.

0700

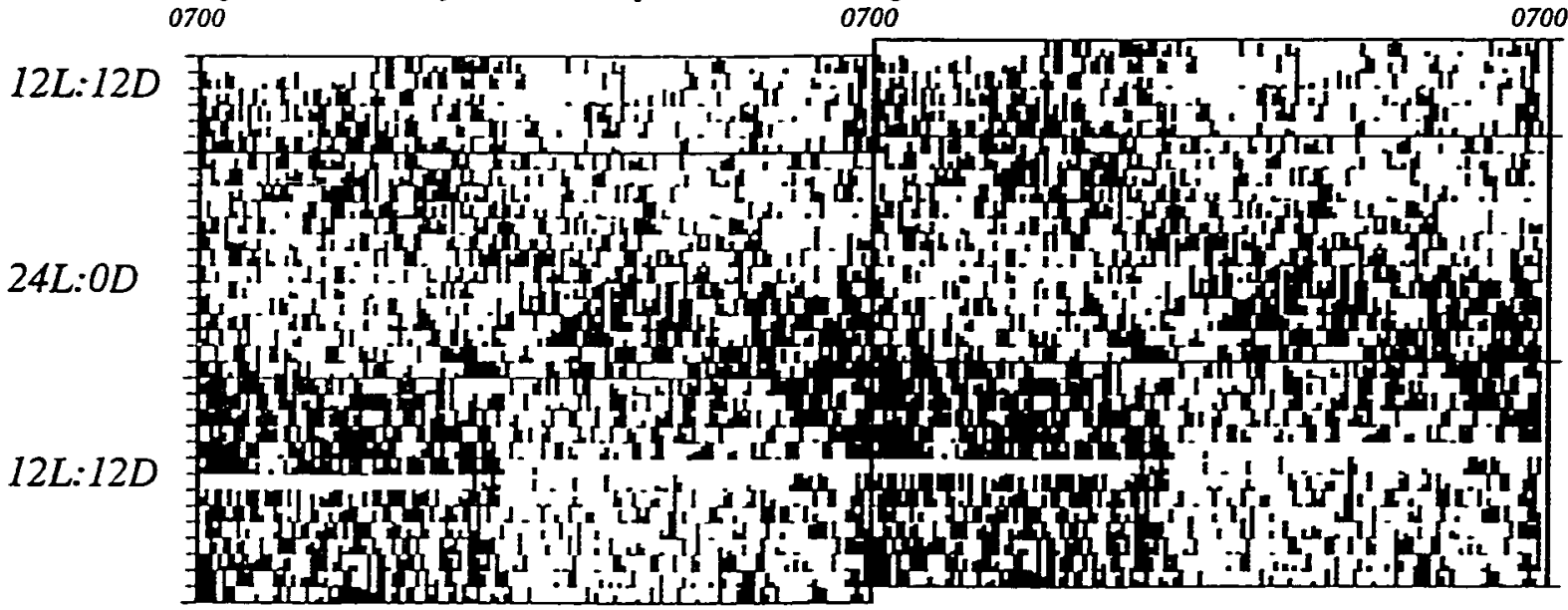

Figure 12. Experiment 9610LEDOIB (1.0 Lux) Rat drinking actogram-CWF. All non-zero values are plotted. Tiventy Four hour epochs are double plotted. 0700

12L:12D

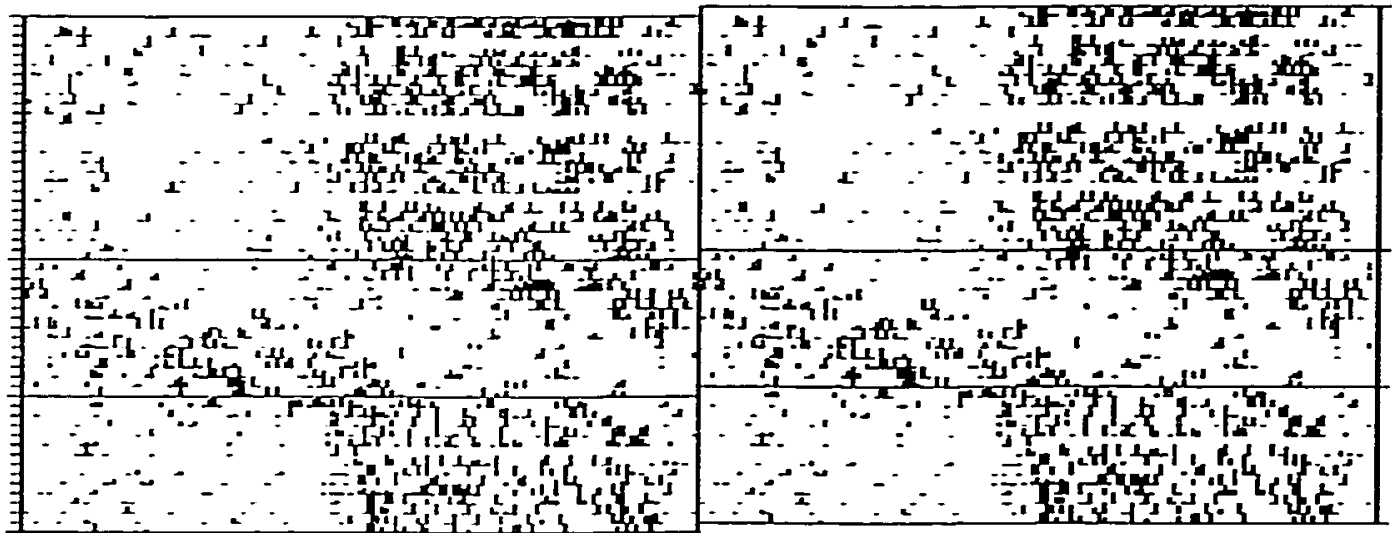

Figure 13. Experiment 9610LEDOIB (1.0 Lux) Rat feeding actogram-CWF. All non-zero values are plotted. Twenty Four hour epochs are double plotted. o700

0700

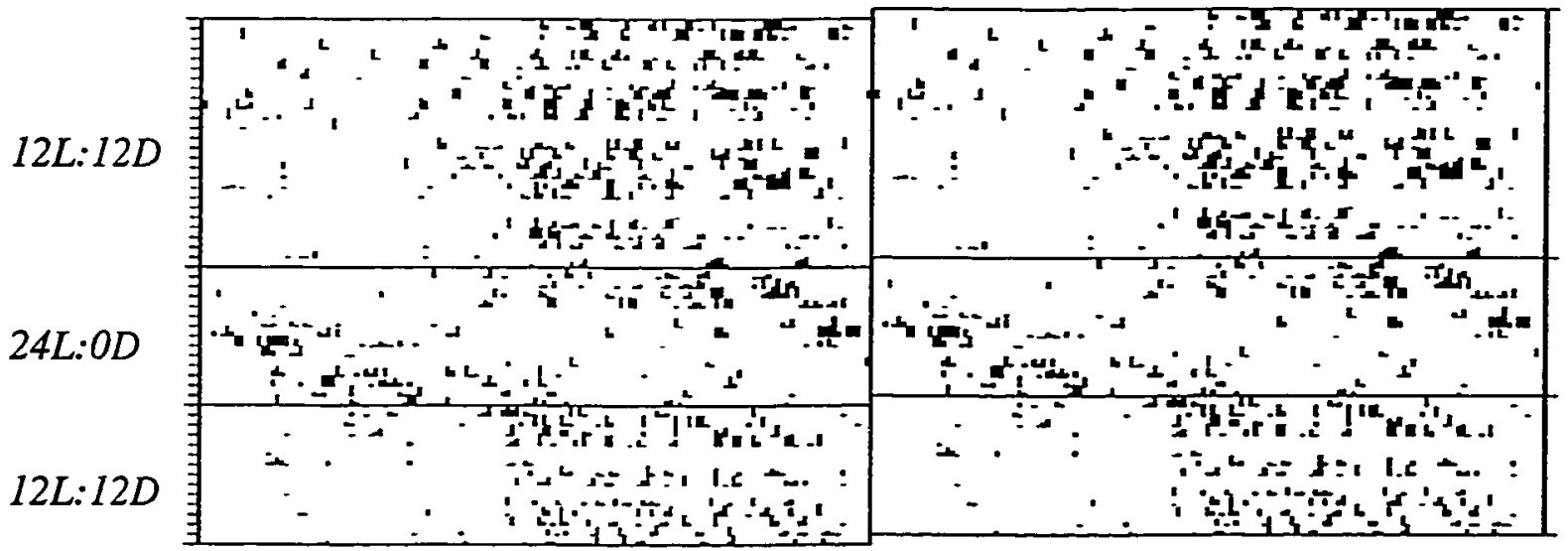


Figure 14. Experiment 9510LEDIO (10 Lux) Rat LMA actogram - LED. All values above the median are plotted. Twenty Four hour epochs are double plotted.

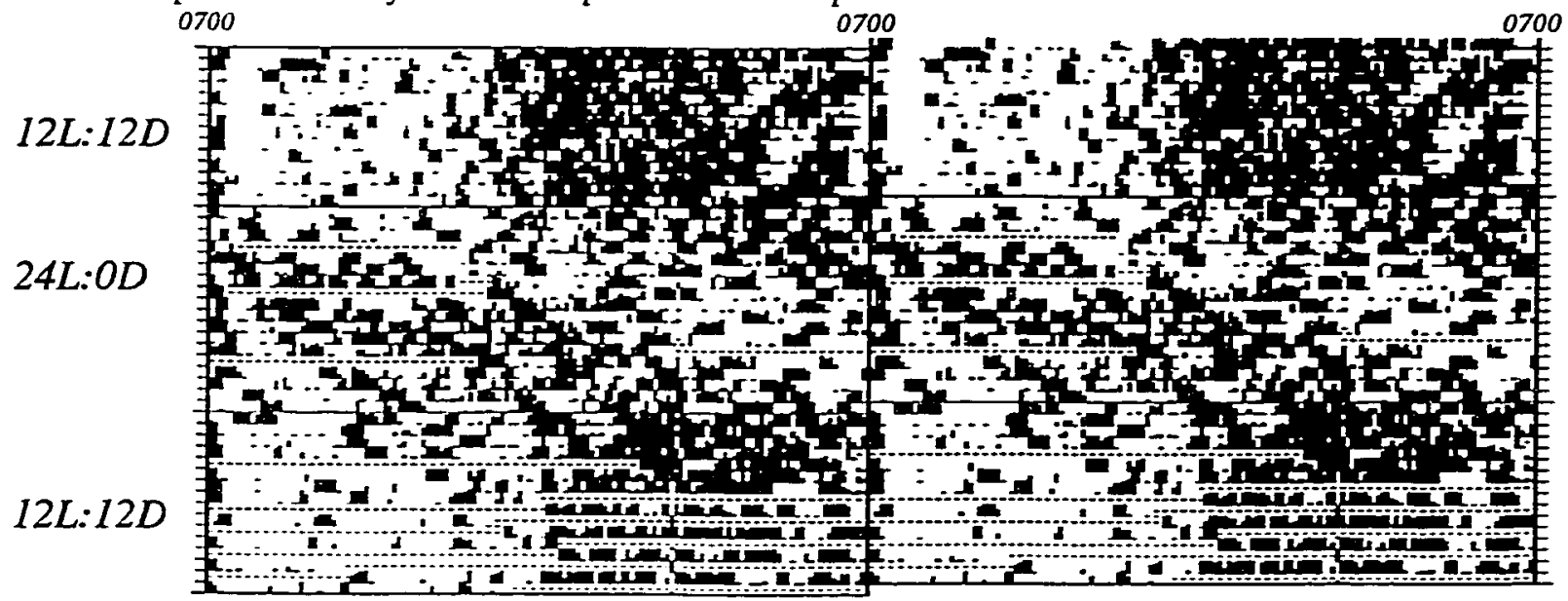

Figure 15. Experiment 9510LED10 (10 LiLx) Rat drinking actogram - LED. All non-zero values are plotted. Twenty Four hour epochs are double plotted. 0700

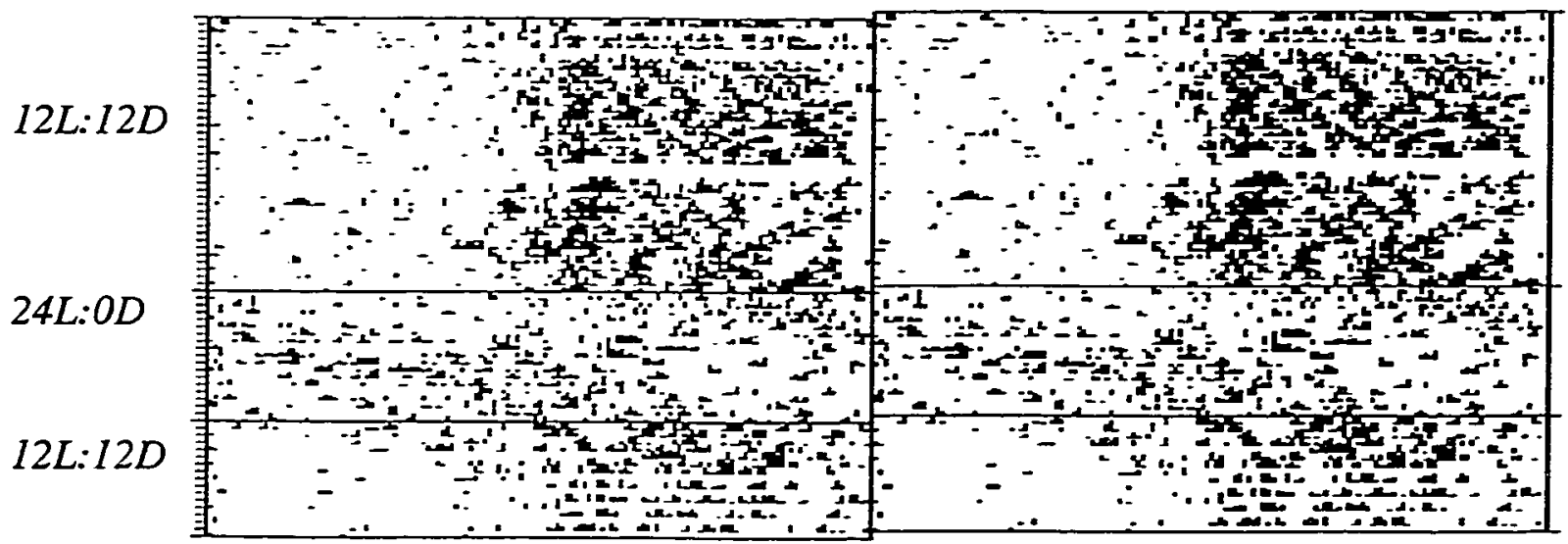

Figure 16. Experiment 9510LED10 (10 LiLx) Rat feeding actogram - LED. All non-zero values are plotted. Twenty Four hour epochs are double plotted.

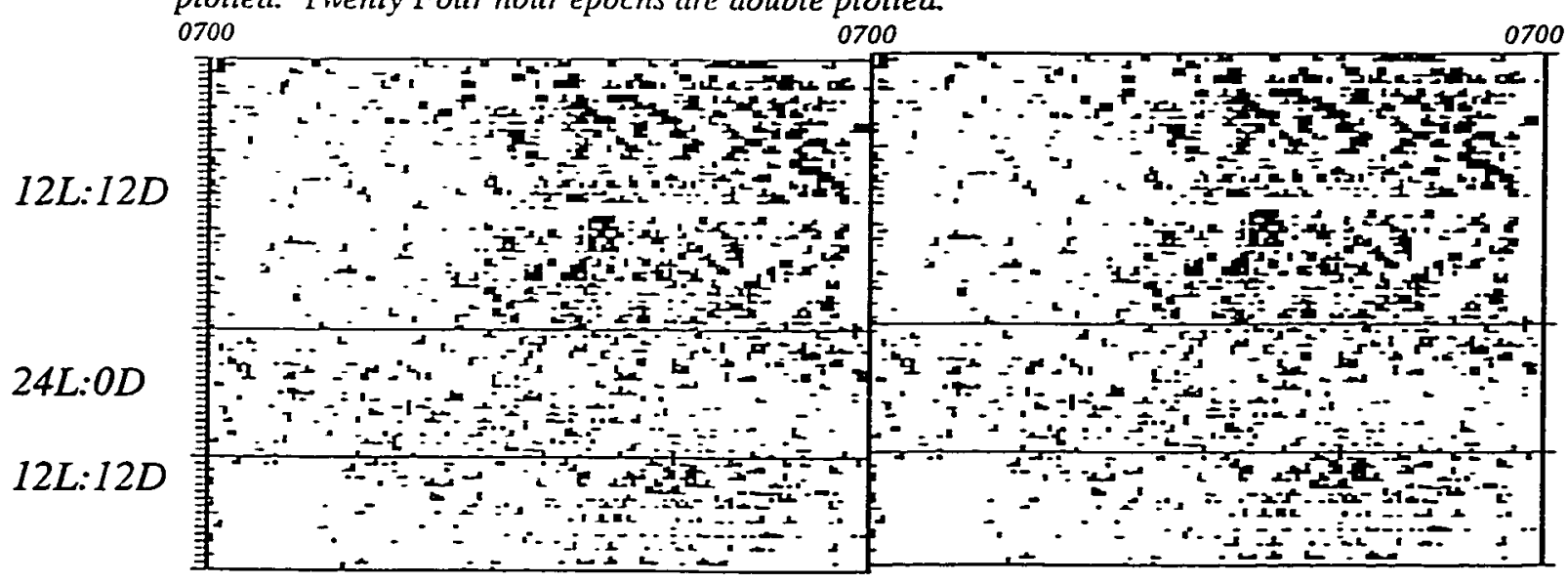


Figure 17. Experiment 9601LED10 (10 Lux) Rat LMA actogram - CWF. All values above the median are plotted. Twenty Four hour epochs are double plotted.

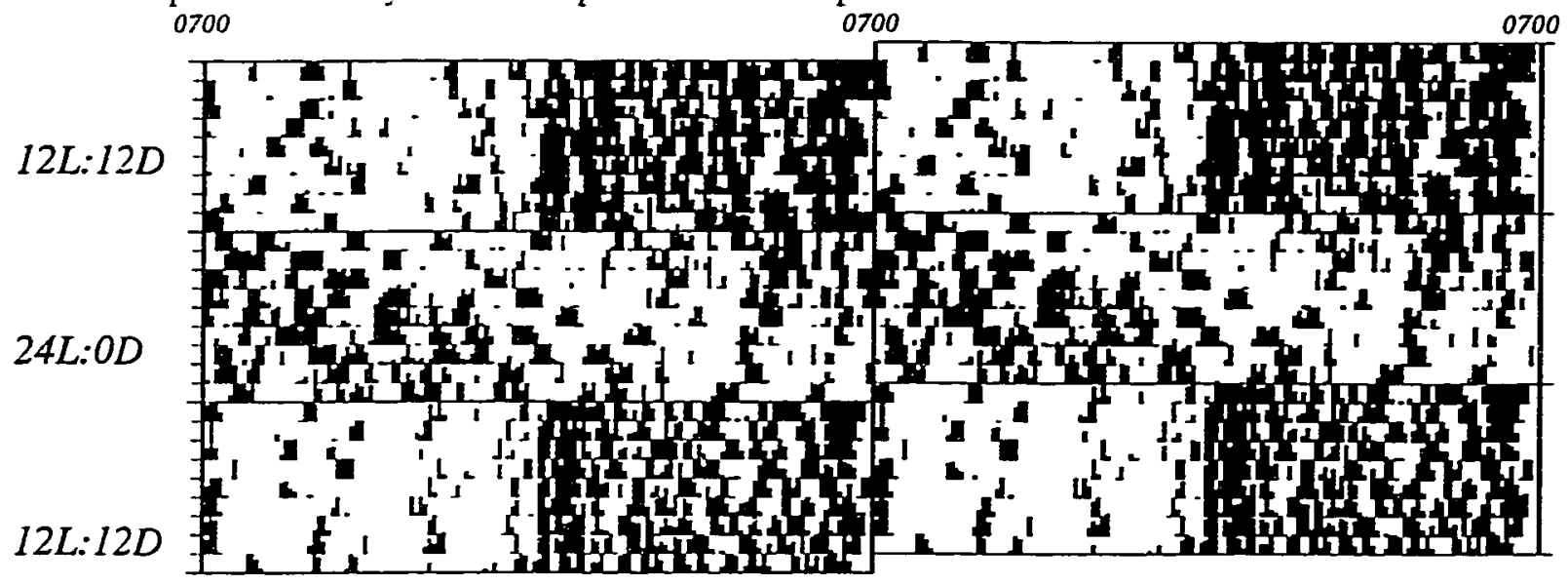

Figure 18. Experiment 9601 LED10 (10 Lux) Rat drinking actogram - CWF. All non-zero values are plotted. Twenty Four hour epochs are double plotted. 0700

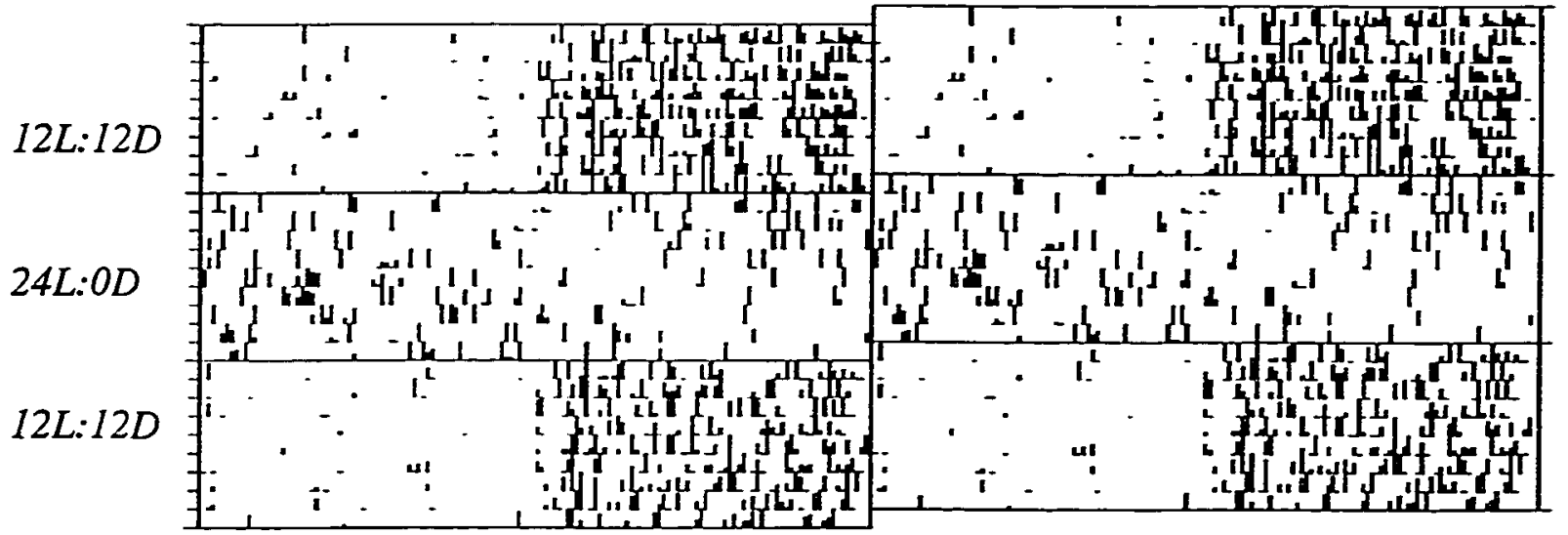

Figure 19. Experiment 9601 LED10 (10 Lux) Rat feeding actogram-CWF. All non-zero values are plotted. Twenty Four hour epochs are double plotted.

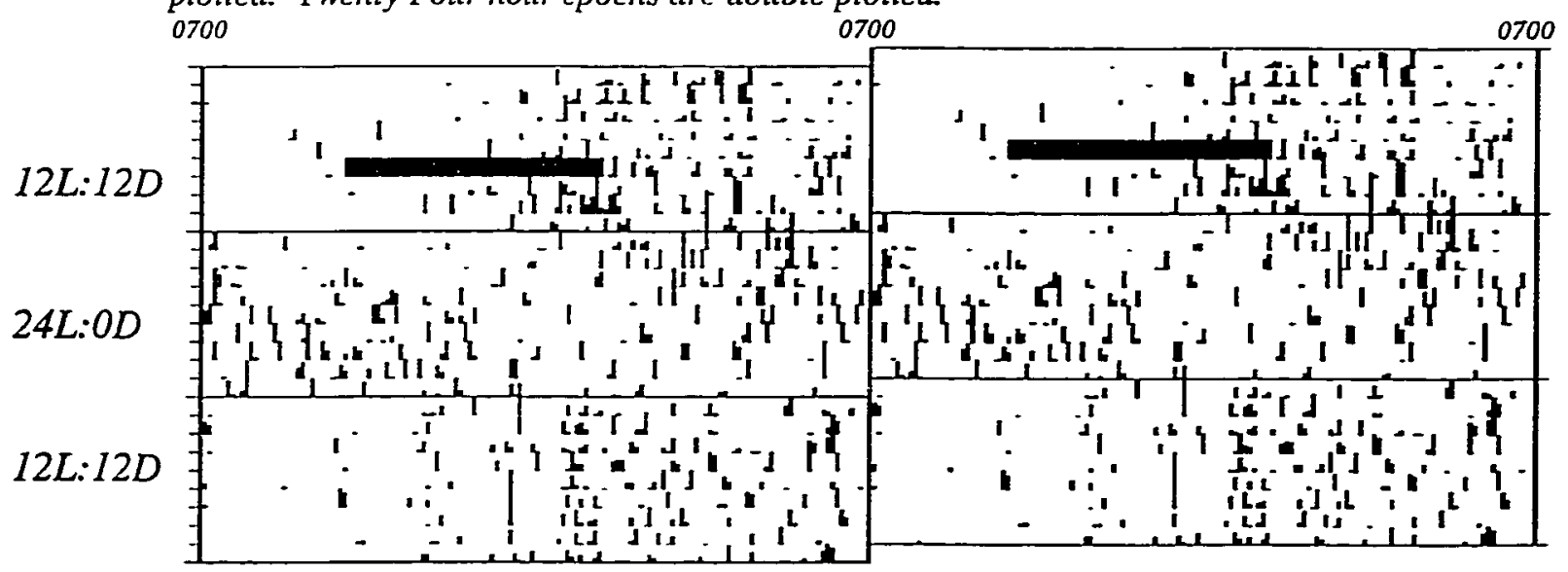


Figure 20. Experiment 9605LED40 (40 LuLx) Rat LMAA actogram - LED. All values above the median are plotted. Twenty Four hour epochs are double plotted.

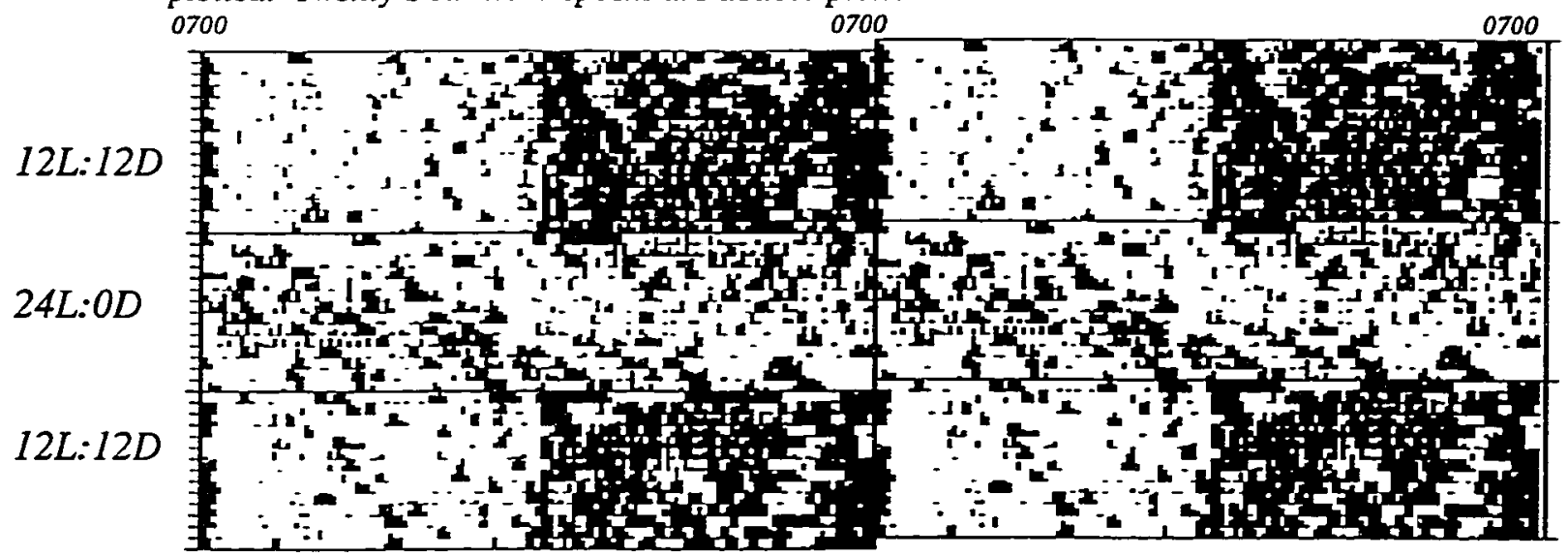

Figure 21. Experiment 9605LED40 (40 Lux) Rat drinking actogram - LED. All non-zero values are plotted. Twenty Four hour epochs are double plotted.

0700

0700

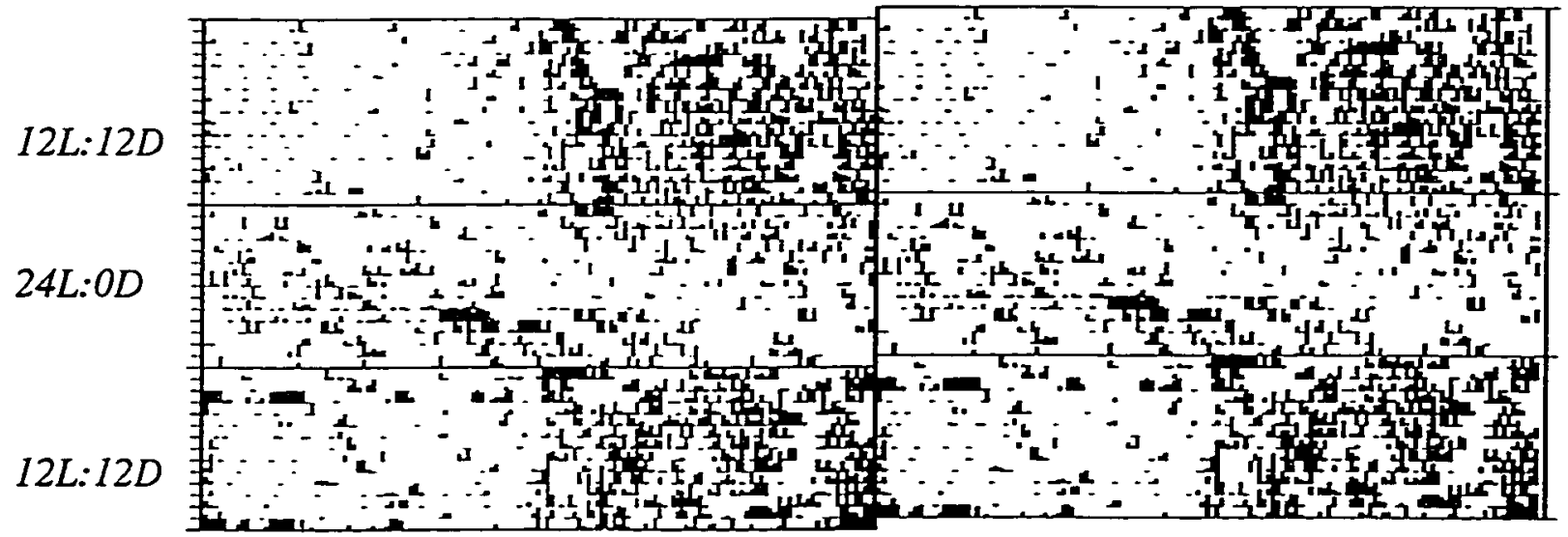

Figure 22. Experiment 9605 LED40 (40 Lux) Rat feeding actogram-LED. All non-zero values are plotted. Twenty Four hour epochs are double plotted.

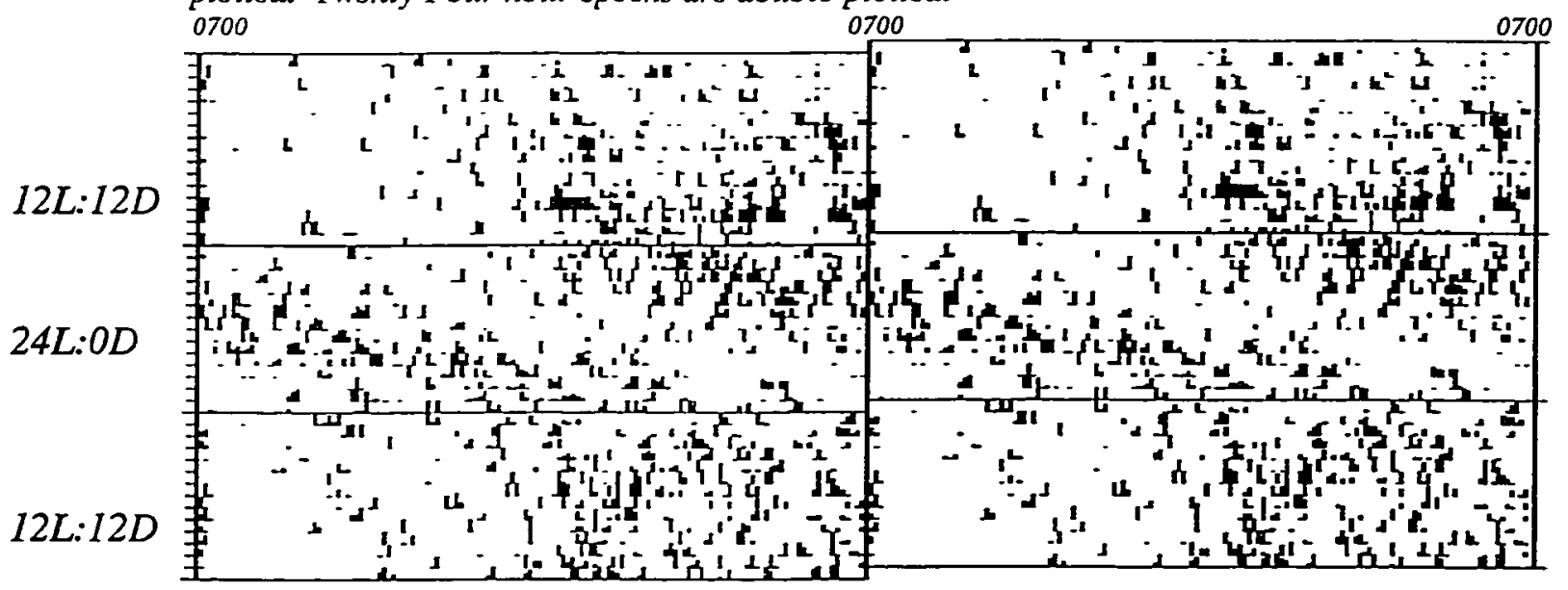


Figure 23. Experiment 9605LED40 (40 Lux) Rat LMA actogram-CWF. All values above the median are plotted. Twenty Four hour epochs are double plotted.

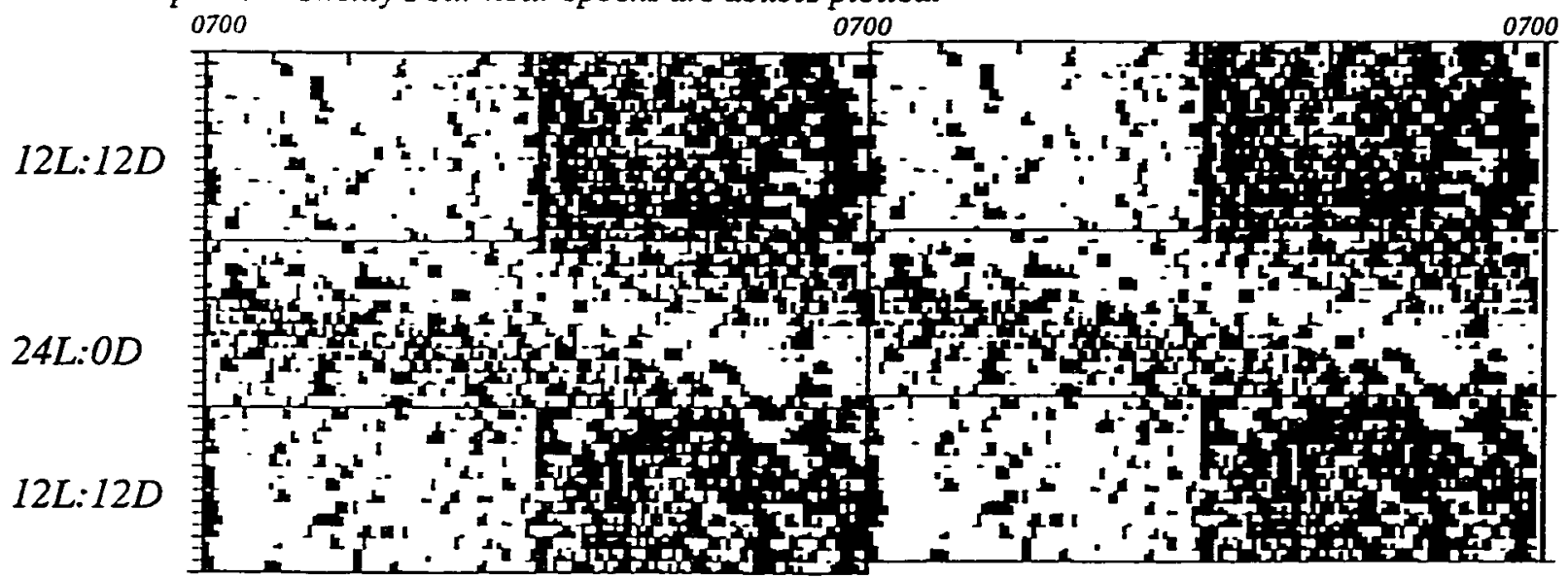

Figure 24. Experiment 9605LED40 (40 Lux) Rat drinking actogram - CWF. All non-zero values are plotted. Twenty Four hour epochs are double plotted. 0700 0700

12L:12D

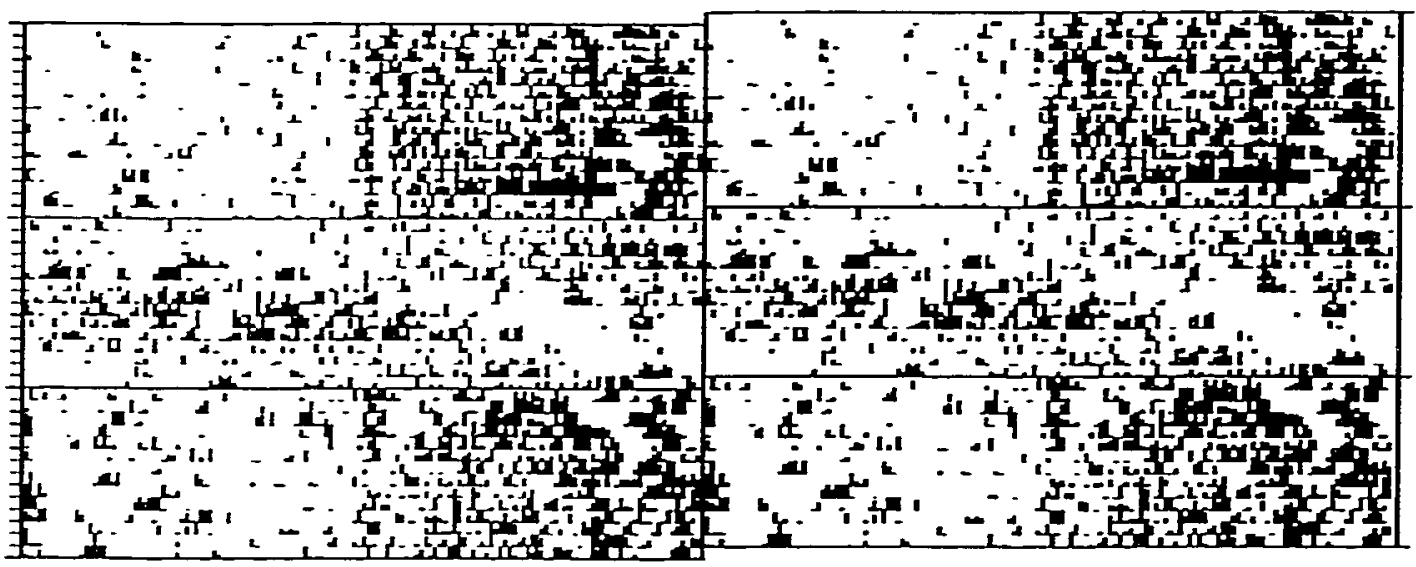

Figure 25. Experiment $9605 L E D 40$ ( 40 Livx) Rat feeding actogram-CWF. All non-zero values are plotted. Twenty Four hour epochs are double plotted.

$12 L: 12 D$

$24 L: O D$ oroo

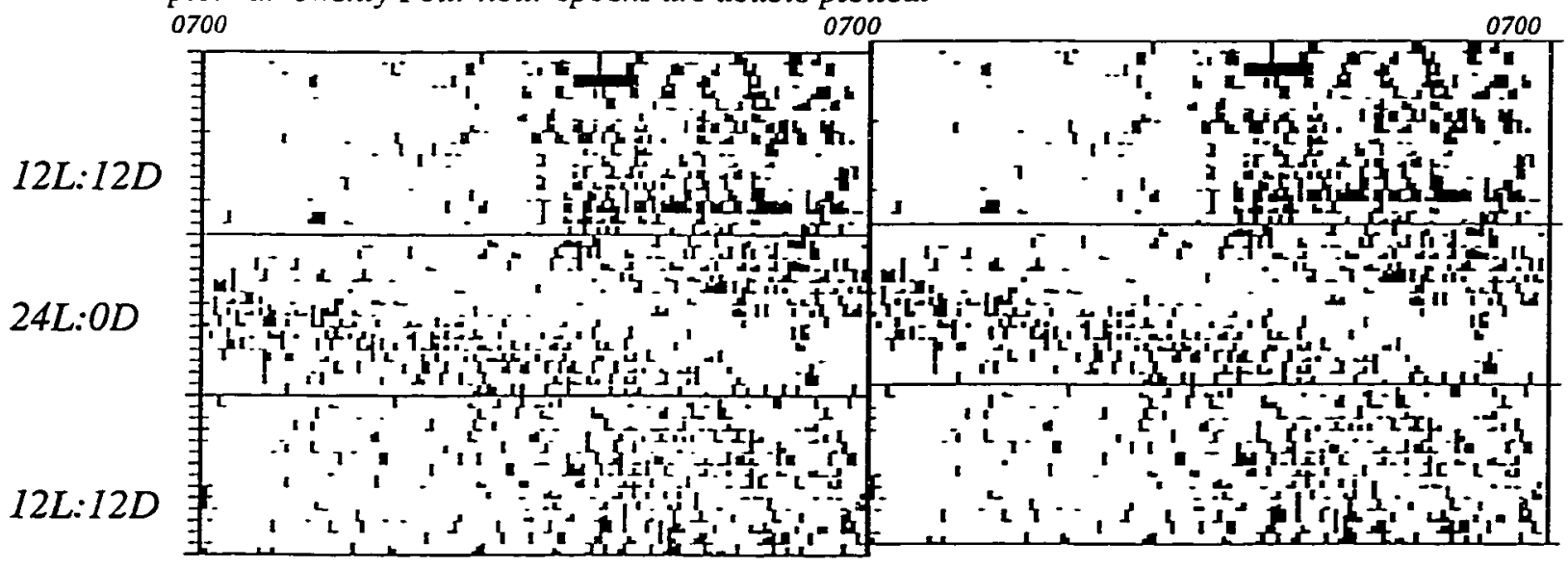


Figure 26. Experiment 9705LED100B (80 Lux) Rat LMA actogram - LED. All values above the median are plotted. Twenty Four hour epochs are double plotted.

0700

0700

$12 L: 12 D$

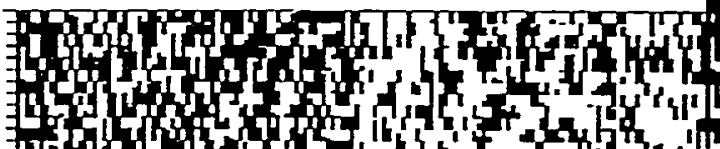

24L:OD
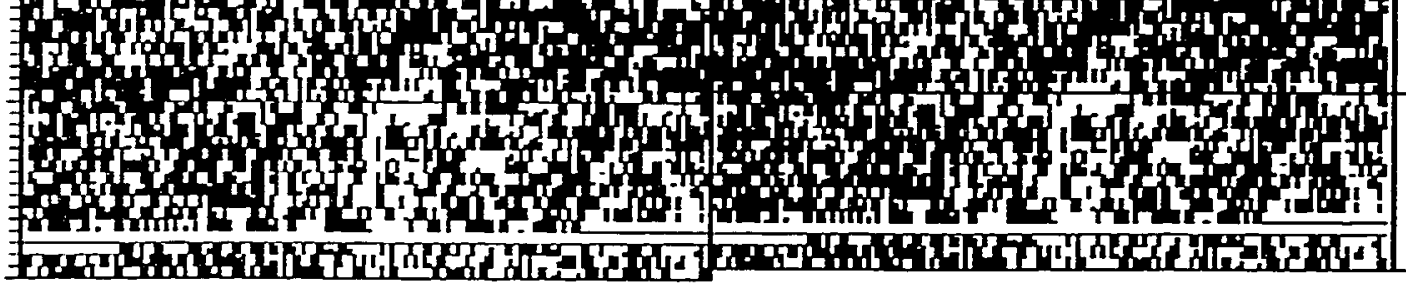

$12 L: 12 D$

Figure 27. Experiment 9705LED100B (80 Lux) Rat drinking actogram - LED. All non-zero values are plotted. Twenty Four hour epochs are double plotted. 0700

$12 L: 12 D$
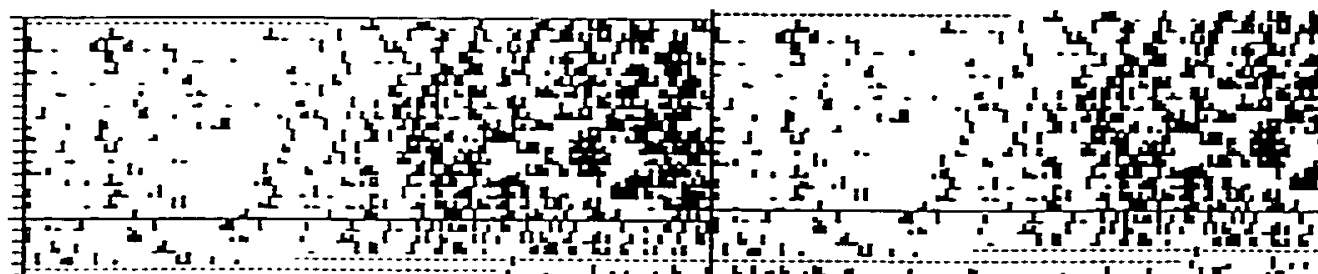

$24 L: O D$

$12 L: 12 D$
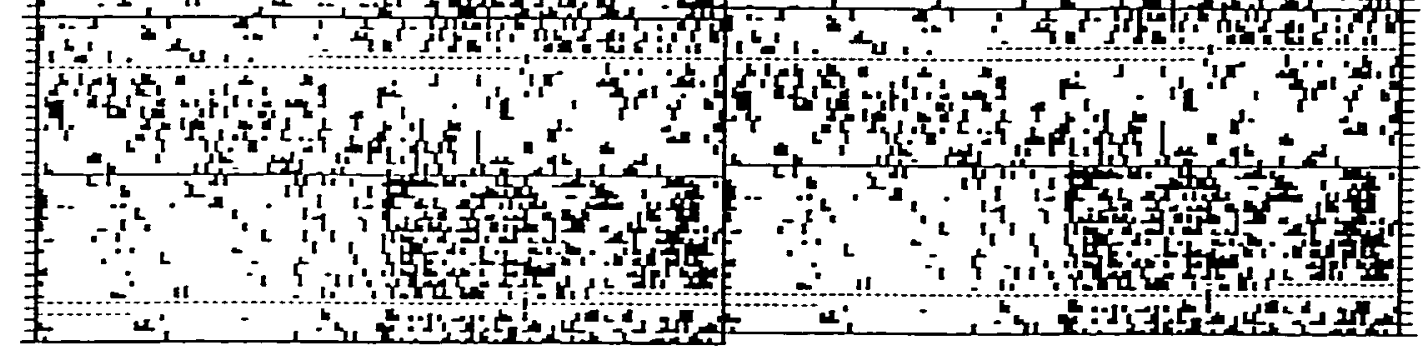

Figure 28. Experiment 9705LEDIOOB (80 Liax) Rat feeding actogram - LED. All non-zero values are plotted. Twenty Four hour epochs are double plotted.

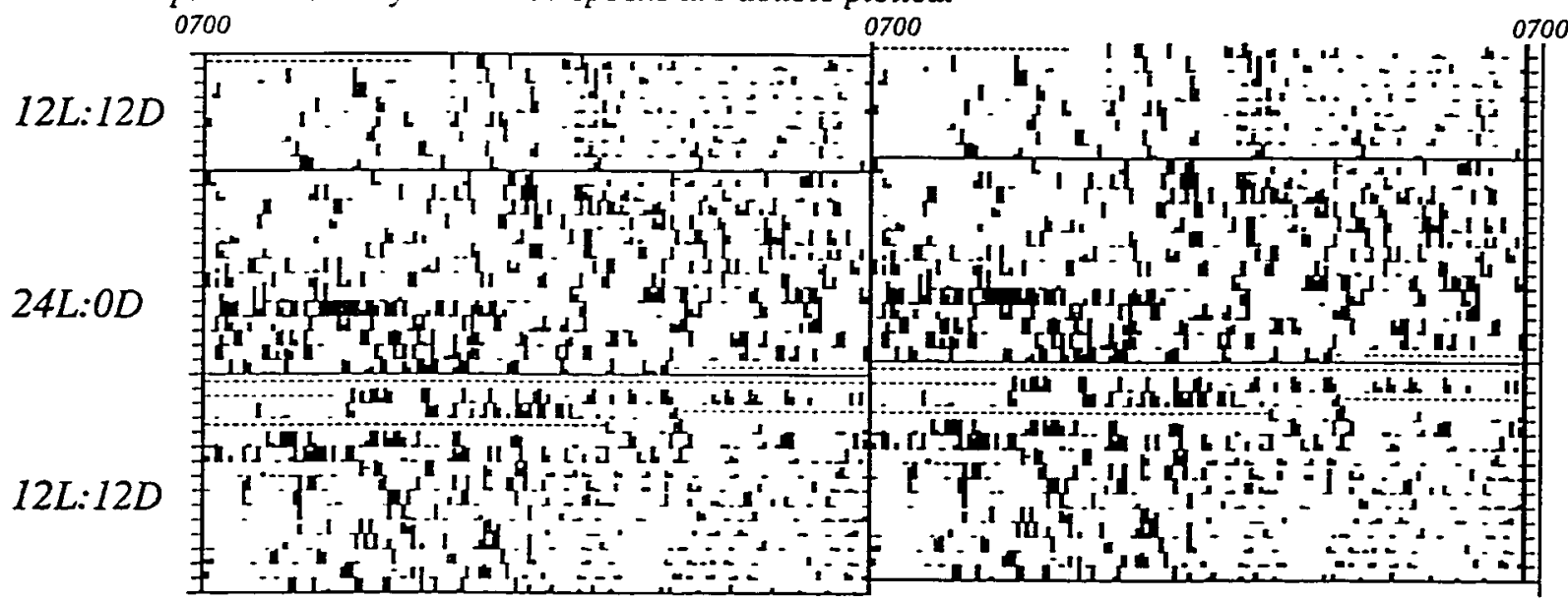


Figure 29. Experiment $9707 L E D 100 B$ (80 Lux) Rat LMA actogram-CWF. All values above the median

are plotted. Twenty Four hour epochs are double plotted.
0700

$12 L: 12 D$

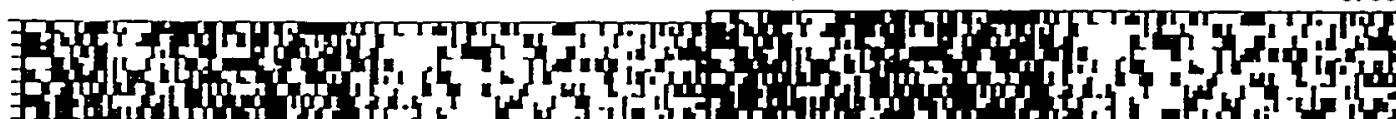

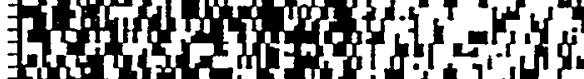

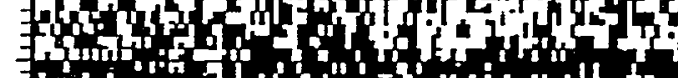

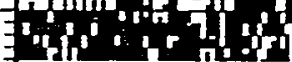

$24 L: O D$

ITI.:IT D

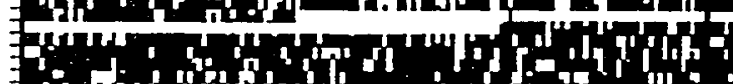

$24 \mathrm{ODO}$

Figure 30.

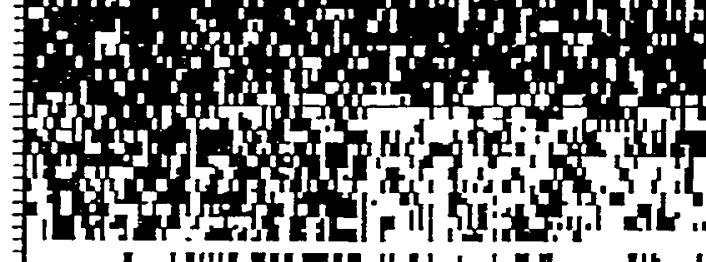

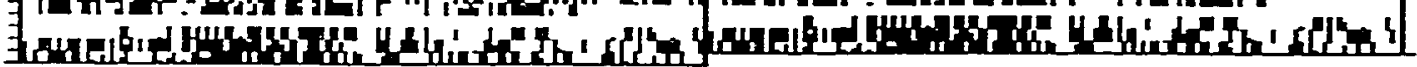

Figure 30. Experiment 9707LED100B (80 Lux) Rat drinking actogram-CWF. All non-zero values are plotted. Twenty Four hour epochs are double plotted. 0700

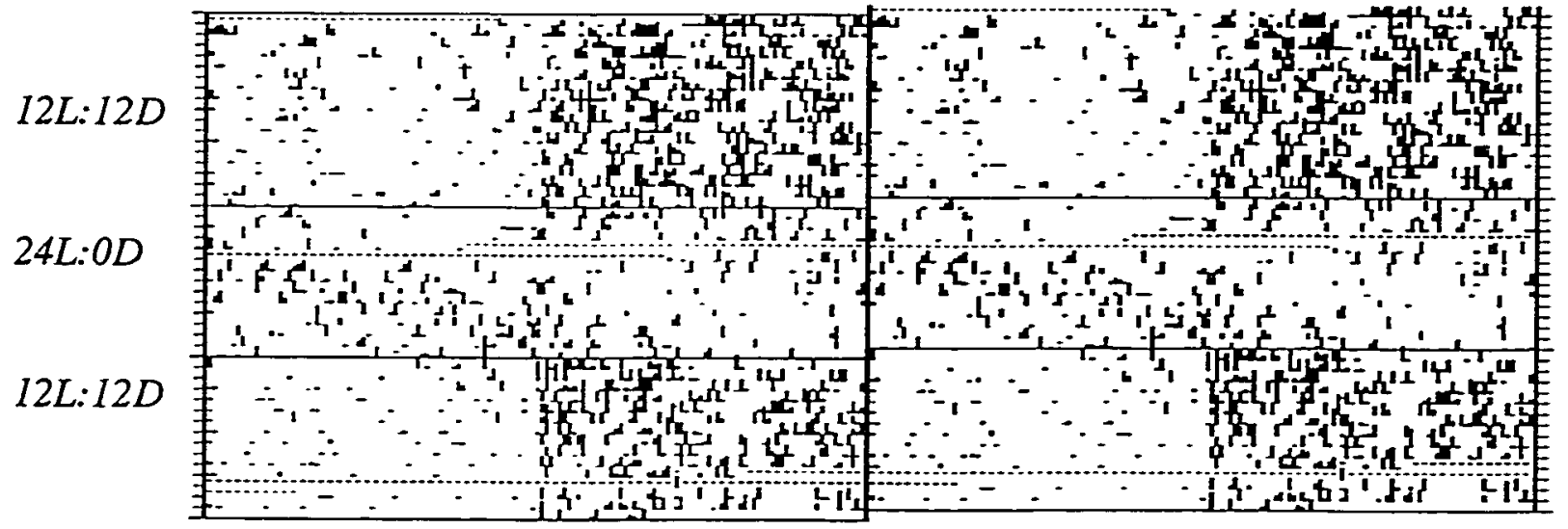

Figure 31. Experiment 9707LEDI00B (80 Lux) Rat feeding actogram - CWF. All non-zero values are plotted. Twenty Four hour epochs are double plotted.

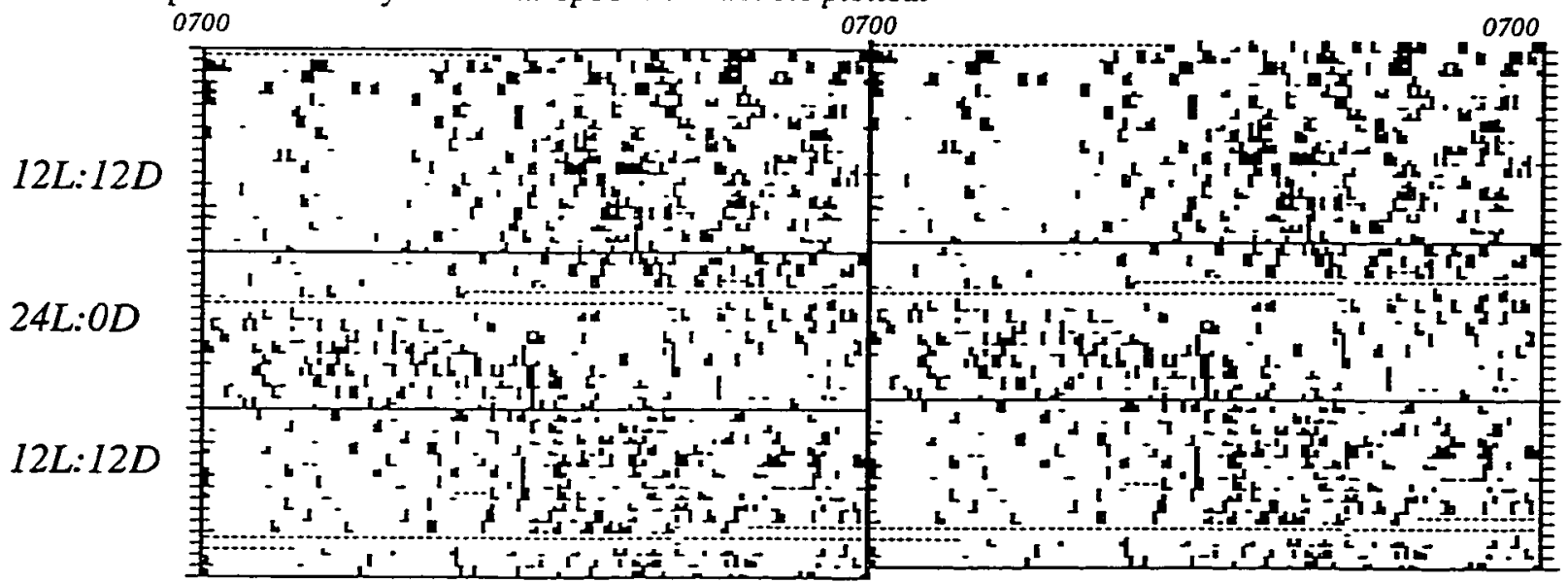


Table 2. Free run periods (tau, hours) for rats kept under constant illumination from cool white fluorescent or RYGB LED panels listed in chronological order.

\begin{tabular}{|c|c|c|c|c|c|c|}
\hline Experiment & Cage \# & Light type & Light level & Activity tau & Drinking tau & Feeding tau \\
\hline $9510 \mathrm{~B}$ & $\begin{array}{l}1 \\
2 \\
3 \\
4 \\
5 \\
6\end{array}$ & $\begin{array}{l}\text { Cool White } \\
\text { LED } \\
\text { LED } \\
\text { LED } \\
\text { Cool White } \\
\text { Cool White }\end{array}$ & $\begin{array}{l}10 \operatorname{lux} \\
10 \operatorname{lux} \\
10 \operatorname{lux} \\
10 \operatorname{lux} \\
10 \operatorname{lux} \\
10 \operatorname{lux} \\
\end{array}$ & $\begin{array}{c}24.5 \\
25.2 \\
25.1 \\
\mathrm{a} \\
24.9 \\
\mathrm{~b} \\
\end{array}$ & $\begin{array}{l}24.2 \\
24.8 \\
24.3 \\
25.7 \\
25.7 \\
24.9 \\
\end{array}$ & $\begin{array}{l}24.4 \\
24.2 \\
24.3 \\
24.1 \\
24.3 \\
24.9 \\
\end{array}$ \\
\hline $9601 B$ & $\begin{array}{l}1 \\
2 \\
3 \\
4 \\
5 \\
6\end{array}$ & $\begin{array}{l}\text { Cool White } \\
\text { LED } \\
\text { LED } \\
\text { LED } \\
\text { Cool White } \\
\text { Cool White }\end{array}$ & $\begin{array}{l}10 \operatorname{lux} \\
10 \operatorname{lux} \\
10 \operatorname{lux} \\
10 \operatorname{lux} \\
10 \operatorname{lux} \\
10 \operatorname{lux} \\
\end{array}$ & $\begin{array}{c}25.6 \\
26.0 \\
25.8 \\
25.6 \\
25.3 \\
\text { b } \\
\end{array}$ & $\begin{array}{l}26.1 \\
25.9 \\
25.6 \\
25.9 \\
25.4 \\
26.0 \\
\end{array}$ & $\begin{array}{l}26.4 \\
26.7 \\
25.3 \\
26.4 \\
25.5 \\
26.4 \\
\end{array}$ \\
\hline $9603 \mathrm{~B}$ & $\begin{array}{l}1 \\
2 \\
3 \\
4 \\
5 \\
6\end{array}$ & $\begin{array}{l}\text { Cool White } \\
\text { LED } \\
\text { LED } \\
\text { LED } \\
\text { Cool White } \\
\text { Cool White }\end{array}$ & $\begin{array}{l}40 \operatorname{lux} \\
10 \operatorname{lux} \\
40 \operatorname{lux} \\
10 \operatorname{lux} \\
10 \operatorname{lux} \\
10 \operatorname{lux} \\
\end{array}$ & $\begin{array}{c}25.9 \\
25.9 \\
25.5 \\
25.5 \\
25.1 \\
b \\
\end{array}$ & $\begin{array}{l}25.9 \\
25.9 \\
25.2 \\
25.2 \\
25.3 \\
25.3 \\
\end{array}$ & $\begin{array}{l}25.8 \\
25.8 \\
25.6 \\
25.2 \\
25.2 \\
25.4 \\
\end{array}$ \\
\hline $9605 \mathrm{~B}$ & $\begin{array}{l}1 \\
2 \\
3 \\
4 \\
5 \\
6\end{array}$ & $\begin{array}{l}\text { Cool White } \\
\text { LED } \\
\text { LED } \\
\text { LED } \\
\text { Cool White } \\
\text { Cool White }\end{array}$ & $\begin{array}{l}40 \operatorname{lux} \\
40 \operatorname{lux} \\
40 \operatorname{lux} \\
40 \operatorname{lux} \\
40 \operatorname{lux} \\
40 \operatorname{lux}\end{array}$ & $\begin{array}{c}25.9 \\
26.1 \\
26.1 \\
26.1 \\
26.1 \\
\text { b } \\
\end{array}$ & $\begin{array}{l}25.8 \\
26.2 \\
26.0 \\
26.1 \\
26.3 \\
25.6 \\
\end{array}$ & $\begin{array}{l}25.9 \\
26.1 \\
25.9 \\
26.2 \\
26.3 \\
25.9 \\
\end{array}$ \\
\hline $9607 \mathrm{~B}$ & $\begin{array}{l}1 \\
2 \\
3 \\
4 \\
5 \\
6\end{array}$ & $\begin{array}{c}\text { Cool White } \\
\text { LED } \\
\text { LED } \\
\text { LED } \\
\text { Cool White } \\
\text { Cool White }\end{array}$ & $\begin{array}{l}40 \operatorname{lux} \\
40 \operatorname{lux} \\
40 \operatorname{lux} \\
40 \operatorname{lux} \\
40 \operatorname{lux} \\
40 \operatorname{lux}\end{array}$ & $\begin{array}{c}25.7 \\
26.0 \\
25.8 \\
25.6 \\
25.8 \\
\text { b } \\
\end{array}$ & $\begin{array}{c}25.7 \\
a \\
25.8 \\
25.6 \\
26.0 \\
25.6 \\
\end{array}$ & $\begin{array}{l}25.8 \\
25.9 \\
25.5 \\
25.6 \\
25.6 \\
25.6 \\
\end{array}$ \\
\hline $9609 \mathrm{~B}, 1$ & $\begin{array}{l}1 \\
2 \\
3 \\
4 \\
5 \\
6 \\
\end{array}$ & $\begin{array}{c}\text { Cool White } \\
\text { LED } \\
\text { LED } \\
\text { LED } \\
\text { Cool White } \\
\text { Cool White }\end{array}$ & $\begin{array}{l}1 \operatorname{lux} \\
1 \operatorname{lux} \\
1 \operatorname{lux} \\
1 \operatorname{lux} \\
1 \operatorname{lux} \\
1 \operatorname{lux} \\
\end{array}$ & $\begin{array}{c}25.8 \\
25.9 \\
26.2 \\
25.7 \\
25.6 \\
\mathrm{~b} \\
\end{array}$ & $\begin{array}{c}25.8 \\
a \\
a \\
25.8 \\
25.6 \\
25.6 \\
\end{array}$ & $\begin{array}{l}25.8 \\
25.8 \\
25.8 \\
26.4 \\
25.9 \\
25.9 \\
\end{array}$ \\
\hline $9610 \mathrm{~B} .1$ & $\begin{array}{l}1 \\
2 \\
3 \\
4 \\
5 \\
6\end{array}$ & $\begin{array}{c}\text { Cool White } \\
\text { LED } \\
\text { LED } \\
\text { LED } \\
\text { Cool White } \\
\text { Cool White }\end{array}$ & $\begin{array}{l}1 \text { lux } \\
1 \text { lux } \\
1 \operatorname{lux} \\
1 \operatorname{lux} \\
1 \operatorname{lux} \\
1 \operatorname{lux} \\
\end{array}$ & $\begin{array}{c}25.3 \\
25.9 \\
25.4 \\
25.3 \\
25.2 \\
\text { b } \\
\end{array}$ & $\begin{array}{c}25.3 \\
a \\
25.2 \\
25.7 \\
25.1 \\
25.8 \\
\end{array}$ & $\begin{array}{l}24.9 \\
25.1 \\
25.6 \\
25.4 \\
25.0 \\
25.3 \\
\end{array}$ \\
\hline $9612 \mathrm{~A} .1$ & $\begin{array}{l}1 \\
2 \\
3 \\
4 \\
5 \\
6\end{array}$ & $\begin{array}{c}\text { LED } \\
\text { Cool White } \\
\text { Cool White } \\
\text { LED } \\
\text { LED } \\
\text { Cool White }\end{array}$ & $\begin{array}{l}1 \text { lux } \\
1 \text { lux } \\
1 \text { lux } \\
1 \text { lux } \\
1 \text { Iux } \\
1 \operatorname{lux}\end{array}$ & $\begin{array}{l}\mathrm{c} \\
\mathrm{c} \\
\mathrm{c} \\
\mathrm{c} \\
\mathrm{c} \\
\mathrm{c}\end{array}$ & $\begin{array}{l}25.8 \\
25.5 \\
25.3 \\
25.5 \\
25.8 \\
25.6 \\
\end{array}$ & $\begin{array}{l}26.0 \\
25.6 \\
25.5 \\
25.4 \\
26.0 \\
25.5 \\
\end{array}$ \\
\hline
\end{tabular}


Table 2(Cont.). Free run periods (tau, hours) for rats kept under constant illumination from cool white fluorescent or RYGB LED panels listed in chronological order.

\begin{tabular}{|c|c|c|c|c|c|c|}
\hline Experiment & Cage \# & Light type & Light level & Activity tau & Drinking tau & Feeding tau \\
\hline $9701 \mathrm{~B}$ & $\begin{array}{l}1 \\
2 \\
3 \\
4 \\
5 \\
6 \\
\end{array}$ & $\begin{array}{c}\text { Cool White } \\
\text { LED } \\
\text { LED } \\
\text { LED } \\
\text { Cool White } \\
\text { Cool White } \\
\end{array}$ & $\begin{array}{l}1 \operatorname{lux} \\
1 \operatorname{lux} \\
1 \operatorname{lux} \\
1 \operatorname{lux} \\
1 \operatorname{lux} \\
1 \operatorname{lux} \\
\end{array}$ & $\begin{array}{c}25.2 \\
25.6 \\
25.1 \\
25.4 \\
25.3 \\
\mathrm{~b} \\
\end{array}$ & $\begin{array}{c}25.4 \\
25.8 \\
25.7 \\
25.9 \\
25.6 \\
\text { a } \\
\end{array}$ & $\begin{array}{l}25.3 \\
25.8 \\
25.8 \\
26.1 \\
25.6 \\
25.7 \\
\end{array}$ \\
\hline $9702 \mathrm{~A}$ & $\begin{array}{l}1 \\
2 \\
3 \\
4 \\
5 \\
6 \\
\end{array}$ & $\begin{array}{c}\text { LED } \\
\text { Cool White } \\
\text { Cool White } \\
\text { LED } \\
\text { LED } \\
\text { Cool White }\end{array}$ & $\begin{array}{l}0.1 \operatorname{lux} \\
0.1 \operatorname{lux} \\
0.1 \operatorname{lux} \\
0.1 \operatorname{lux} \\
0.1 \operatorname{lux} \\
0.1 \operatorname{lux} \\
\end{array}$ & $\begin{array}{l}\text { c } \\
c \\
c \\
c \\
c \\
c\end{array}$ & $\begin{array}{l}24.4 \\
24.7 \\
24.6 \\
24.5 \\
24.1 \\
24.2 \\
\end{array}$ & \begin{tabular}{l|}
24.0 \\
24.4 \\
24.6 \\
24.5 \\
24.1 \\
24.8 \\
\end{tabular} \\
\hline $9703 \mathrm{~B}$ & $\begin{array}{l}1 \\
2 \\
3 \\
4 \\
5 \\
6 \\
\end{array}$ & $\begin{array}{l}\text { Cool White } \\
\text { LED } \\
\text { LED } \\
\text { LED } \\
\text { Cool White } \\
\text { Cool White }\end{array}$ & $\begin{array}{l}0.1 \operatorname{lux} \\
0.1 \operatorname{lux} \\
0.1 \operatorname{lux} \\
0.1 \operatorname{lux} \\
0.1 \operatorname{lux} \\
0.1 \operatorname{lux} \\
\end{array}$ & $\begin{array}{c}24.4 \\
24.4 \\
24.7 \\
24.7 \\
24.2 \\
\text { b } \\
\end{array}$ & $\begin{array}{l}24.4 \\
24.4 \\
24.7 \\
24.8 \\
24.4 \\
24.6 \\
\end{array}$ & $\begin{array}{l}24.5 \\
24.6 \\
24.7 \\
25.2 \\
24.4 \\
24.7 \\
\end{array}$ \\
\hline $9704 \mathrm{~A}$ & $\begin{array}{l}1 \\
2 \\
3 \\
4 \\
5 \\
6 \\
\end{array}$ & $\begin{array}{c}\text { LED } \\
\text { Cool White } \\
\text { Cool White } \\
\text { LED } \\
\text { LED } \\
\text { Cool White }\end{array}$ & $\begin{array}{l}0.1 \operatorname{lux} \\
0.1 \operatorname{lux} \\
0.1 \operatorname{lux} \\
0.1 \operatorname{lux} \\
0.1 \operatorname{lux} \\
0.1 \operatorname{lux} \\
\end{array}$ & $\begin{array}{l}\text { c } \\
c \\
c \\
c \\
c \\
c \\
\end{array}$ & $\begin{array}{c}25.1 \\
24.4 \\
24.8 \\
\text { a } \\
25.1 \\
\text { a } \\
\end{array}$ & $\begin{array}{l}25.3 \\
25.3 \\
24.3 \\
25.8 \\
24.7 \\
24.9\end{array}$ \\
\hline $9705 \mathrm{~B}$ & $\begin{array}{l}1 \\
2 \\
3 \\
4 \\
5 \\
6 \\
\end{array}$ & $\begin{array}{l}\text { Cool White } \\
\text { LED } \\
\text { LED } \\
\text { LED } \\
\text { Cool White } \\
\text { Cool White }\end{array}$ & $\begin{array}{l}80 \operatorname{lux} \\
80 \operatorname{lux} \\
80 \operatorname{lux} \\
80 \operatorname{lux} \\
80 \operatorname{lux} \\
80 \operatorname{lux}\end{array}$ & $\begin{array}{c}26.6 \\
25.9 \\
26.5 \\
a \\
26.4 \\
\text { b }\end{array}$ & \begin{tabular}{l|}
26.2 \\
26.3 \\
26.3 \\
26.2 \\
26.6 \\
25.3 \\
\end{tabular} & $\begin{array}{c}26.5 \\
25.8 \\
a \\
26.4 \\
26.5 \\
26.6\end{array}$ \\
\hline $9707 \mathrm{~A}$ & $\begin{array}{l}1 \\
2 \\
3 \\
4 \\
5 \\
6\end{array}$ & $\begin{array}{c}\text { LED } \\
\text { Cool White } \\
\text { Cool White } \\
\text { LED } \\
\text { LED } \\
\text { Cool White }\end{array}$ & $\begin{array}{l}80 \operatorname{lux} \\
80 \operatorname{lux} \\
80 \operatorname{lux} \\
80 \operatorname{lux} \\
80 \operatorname{lux} \\
80 \operatorname{lux}\end{array}$ & $\begin{array}{l}c \\
c \\
c \\
c \\
c \\
c\end{array}$ & $\begin{array}{c}25.9 \\
24.8 \\
25.7 \\
25.7 \\
a \\
25.3\end{array}$ & $\begin{array}{c}25.8 \\
25.5 \\
25.9 \\
25.6 \\
a \\
25.5\end{array}$ \\
\hline $9707 \mathrm{~B}$ & $\begin{array}{l}1 \\
2 \\
3 \\
4 \\
5 \\
6\end{array}$ & $\begin{array}{l}\text { Cool White } \\
\text { LED } \\
\text { LED } \\
\text { LED } \\
\text { Cool White } \\
\text { Cool White }\end{array}$ & $\begin{array}{l}80 \operatorname{lux} \\
80 \operatorname{lux} \\
80 \operatorname{lux} \\
80 \operatorname{lux} \\
80 \operatorname{lux} \\
80 \operatorname{lux} \\
\end{array}$ & $\begin{array}{c}25.9 \\
26.3 \\
25.5 \\
\mathrm{a} \\
\mathrm{a} \\
\mathrm{b} \\
\end{array}$ & $\begin{array}{l}25.5 \\
25.7 \\
25.3 \\
25.9 \\
25.5 \\
25.6 \\
\end{array}$ & $\begin{array}{c}26.2 \\
\mathrm{a} \\
\mathrm{a} \\
\mathrm{a} \\
25.8 \\
26.3\end{array}$ \\
\hline
\end{tabular}

a Tau could not be determined.

b No activity data collected in this cage due to a broken accelerometer.

c Since cages were not equipped with activily sensors, data for this parameter were not collected. 
Table 3. Individual free run periods (tau, hours) for rats kept under constant illumination from cool white fluorescent or RYGB LED panels listed by light level. Each row represents data from one animal.

\begin{tabular}{|c|c|c|c|c|c|c|}
\hline \multirow[b]{2}{*}{ Light Level } & \multicolumn{2}{|c|}{ Activity } & \multicolumn{2}{|c|}{ Drinking } & \multicolumn{2}{|c|}{ Feeding } \\
\hline & Cool White & LED & Cool White & LED & Cool White & LED \\
\hline \multirow[t]{9}{*}{0.1 lux } & & & 24.7 & 24.4 & 24.4 & 24.0 \\
\hline & & & 24.6 & 24.5 & 24.6 & 24.5 \\
\hline & & & 24.2 & 24.1 & 24.8 & 24.1 \\
\hline & 24.4 & 24.4 & 24.4 & 24.4 & 24.5 & 24.6 \\
\hline & 24.2 & 24.7 & 24.4 & 24.7 & 24.4 & 24.7 \\
\hline & & 24.7 & 24.6 & 24.8 & 24.7 & 25.2 \\
\hline & & & 24.4 & 25.1 & 25.3 & 25.3 \\
\hline & & & 24.8 & & 24.3 & 25.8 \\
\hline & & & & 25.1 & 24.9 & 24.7 \\
\hline \multirow[t]{12}{*}{$1 \operatorname{lux}$} & 25.8 & 25.9 & 25.8 & & 25.8 & 25.8 \\
\hline & 25.6 & 26.2 & 25.6 & & 25.9 & 25.8 \\
\hline & & 25.7 & 25.6 & 25.8 & 25.9 & 26.4 \\
\hline & 25.3 & 25.9 & 25.3 & & 24.9 & 25.1 \\
\hline & 25.2 & 25.4 & 25.1 & 25.2 & 25.0 & 25.6 \\
\hline & & 25.3 & 25.8 & 25.7 & 25.3 & 25.4 \\
\hline & & & 25.5 & 25.8 & 25.6 & 26.0 \\
\hline & & & 25.3 & 25.5 & 25.5 & 25.4 \\
\hline & & & 25.6 & 25.8 & 25.5 & 26.0 \\
\hline & 25.2 & 25.6 & 25.4 & 25.8 & 25.3 & 25.8 \\
\hline & 25.3 & 25.1 & 25.6 & 25.7 & 25.6 & 25.8 \\
\hline & & 25.4 & & 25.9 & 25.7 & 26.1 \\
\hline \multirow[t]{8}{*}{$10 \operatorname{lux}$} & 24.5 & 25.2 & 24.2 & 24.8 & 24.4 & 24.2 \\
\hline & 24.9 & 25.1 & 25.7 & 24.3 & 24.3 & 24.3 \\
\hline & & & 24.9 & 25.7 & 24.9 & 24.1 \\
\hline & 25.6 & 26.0 & 26.1 & 25.9 & 26.4 & 26.7 \\
\hline & 25.3 & 25.8 & 25.4 & 25.6 & & \\
\hline & & 25.6 & 26.0 & 25.9 & 26.4 & 26.4 \\
\hline & 25.1 & 25.9 & 25.3 & 25.9 & 25.2 & 25.8 \\
\hline & & 25.5 & 25.3 & 25.2 & 25.4 & 25.2 \\
\hline \multirow[t]{7}{*}{$40 \operatorname{lu} x$} & 25.9 & 25.5 & 25.9 & 25.2 & 25.8 & 25.6 \\
\hline & 25.9 & 26.1 & 25.8 & 26.2 & 25.9 & 26.1 \\
\hline & 26.1 & 26.1 & 26.3 & 26.0 & 26.3 & 25.9 \\
\hline & & 26.1 & 25.6 & 26.1 & 25.9 & 26.2 \\
\hline & 25.7 & 26.0 & 25.7 & & 25.8 & 25.9 \\
\hline & 25.8 & 25.8 & 26.0 & 25.8 & 25.6 & 25.5 \\
\hline & & 25.6 & 25.6 & 25.6 & 25.6 & 25.6 \\
\hline \multirow[t]{9}{*}{$80 \operatorname{lux}$} & 26.6 & 25.9 & 26.2 & 26.3 & 26.5 & 25.8 \\
\hline & 26.4 & 26.5 & 26.6 & 26.3 & 26.5 & \\
\hline & & & 25.3 & 26.2 & 26.6 & 26.4 \\
\hline & & & 24.8 & 25.9 & 25.5 & 25.8 \\
\hline & & & 25.7 & 25.7 & 25.9 & 25.6 \\
\hline & & & 25.3 & & 25.5 & \\
\hline & 25.9 & 26.3 & 25.5 & 25.7 & 26.2 & \\
\hline & & 25.5 & 25.5 & 25.3 & 25.8 & \\
\hline & & & 25.6 & 25.9 & 26.3 & \\
\hline
\end{tabular}




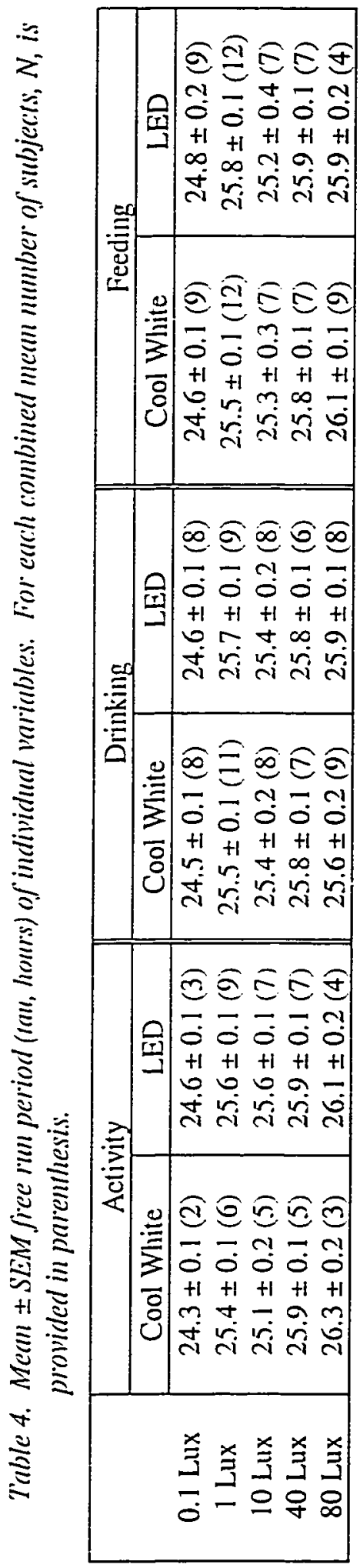


Table 5. Mean $\pm S E M$ free run period (tau, hours) of combined variables.

\begin{tabular}{|c|c|c||}
\hline & \multicolumn{2}{|c||}{ mean of Activity, Drinking, and Feeding } \\
\hline & Cool White & LED \\
\hline 0.1 Lux & $24.6 \pm 0.1$ & $24.7 \pm 0.2$ \\
1 Lux & $25.5 \pm 0.1$ & $25.7 \pm 0.1$ \\
10 Lux & $25.3 \pm 0.2$ & $25.4 \pm 0.2$ \\
40 Lux & $25.8 \pm 0.1$ & $25.9 \pm 0.1$ \\
80 Lux & $25.9 \pm 0.1$ & $25.9 \pm 0.1$ \\
\hline
\end{tabular}

Table 6. ANOVA table for the analysis of combined free run periods.

\begin{tabular}{|l|r|r|r|c|}
\hline & df & \multicolumn{1}{|c|}{ SS } & MS & F \\
\hline \hline light type & 1 & 0.407 & 0.407 & 1.284 \\
\hline light level & 4 & 46.863 & 11.716 & $36.924^{* *}$ \\
\hline type vs. level interaction & 4 & 0.342 & 0.086 & 0.270 \\
\hline rats within type vs. level & 79 & 25.066 & 0.317 & $4.061^{* *}$ \\
\hline within animals & 129 & 10.079 & 0.078 & \\
\hline total & 217 & 82.759 & & \\
\hline
\end{tabular}

Table 7. Planned comparisons among light levels.

\begin{tabular}{|l|c|c|c|c|}
\hline & df & SS & MS & F \\
\hline \hline 0.1 vs. $1 \operatorname{lux}$ & 1 & 22.462 & 22.462 & 70.791 \\
\hline 1 vs. $10 \operatorname{lux}$ & 1 & 1.664 & 1.664 & 5.246 \\
\hline 10 vs. $80 \operatorname{lux}$ & 1 & 6.929 & 6.929 & 21.838 \\
\hline 40 vs. $80 \operatorname{lux}$ & 1 & 0.111 & 0.111 & 0.349 \\
\hline
\end{tabular}


Figure 32. Combined mean \pm SEMI free run period (tau, hours) for rats kept under constant illumination from cool white fluorescent or LED panels. There was no difference between LED and Cool White Fluorescent means at each light intensity, ANOVA $(p<0.05)$.

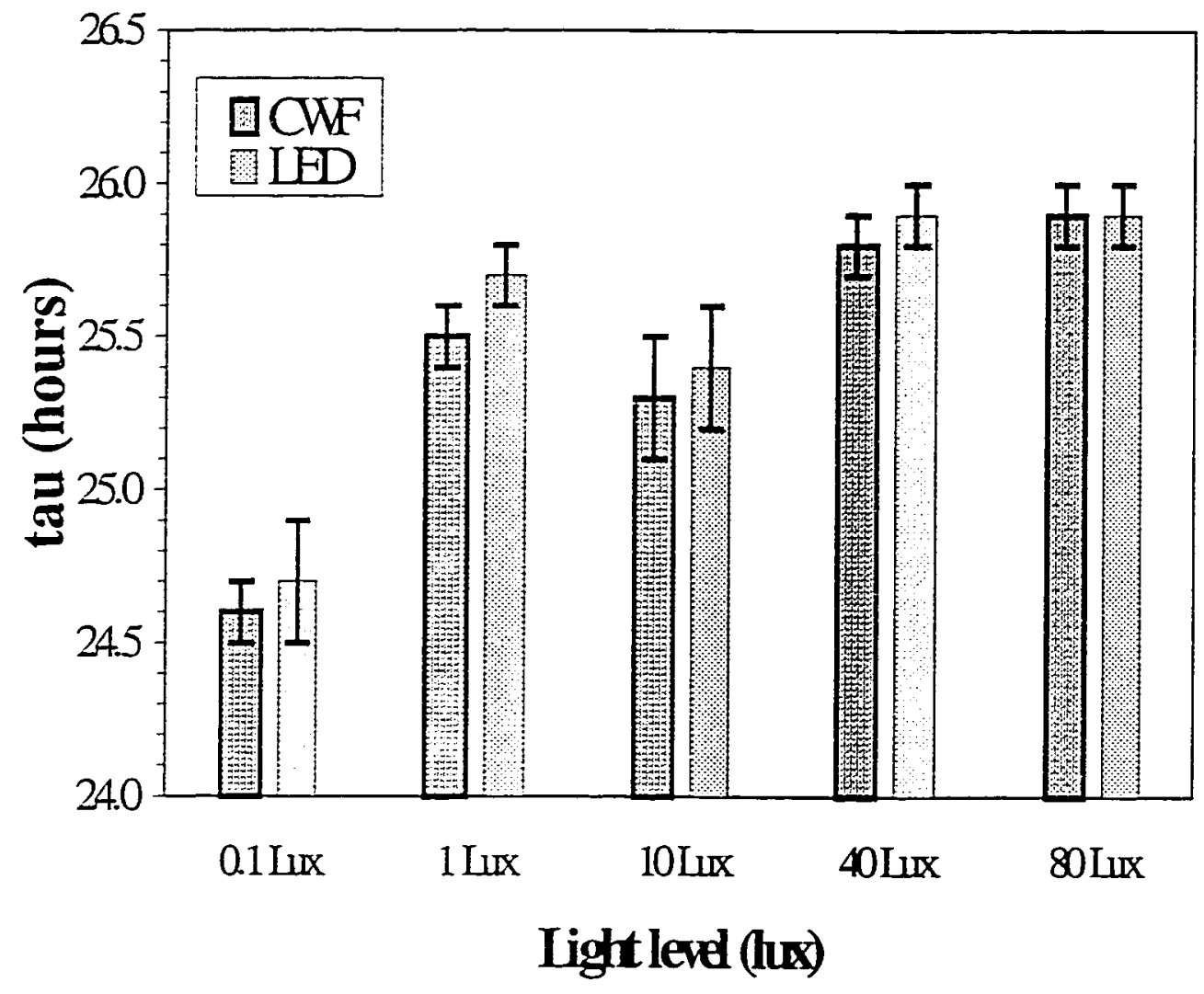


Figure 33. 4-color LED panel schematic.

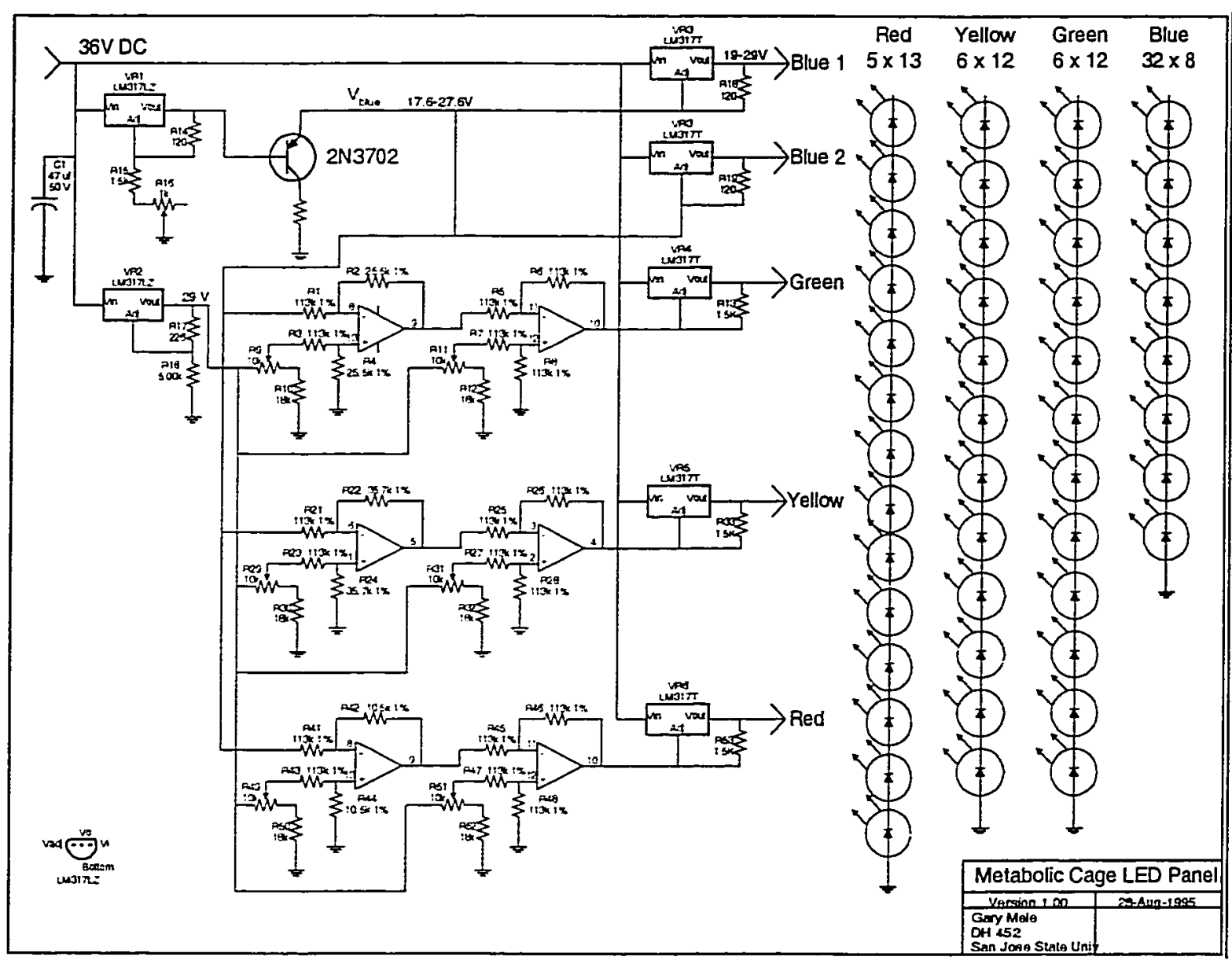



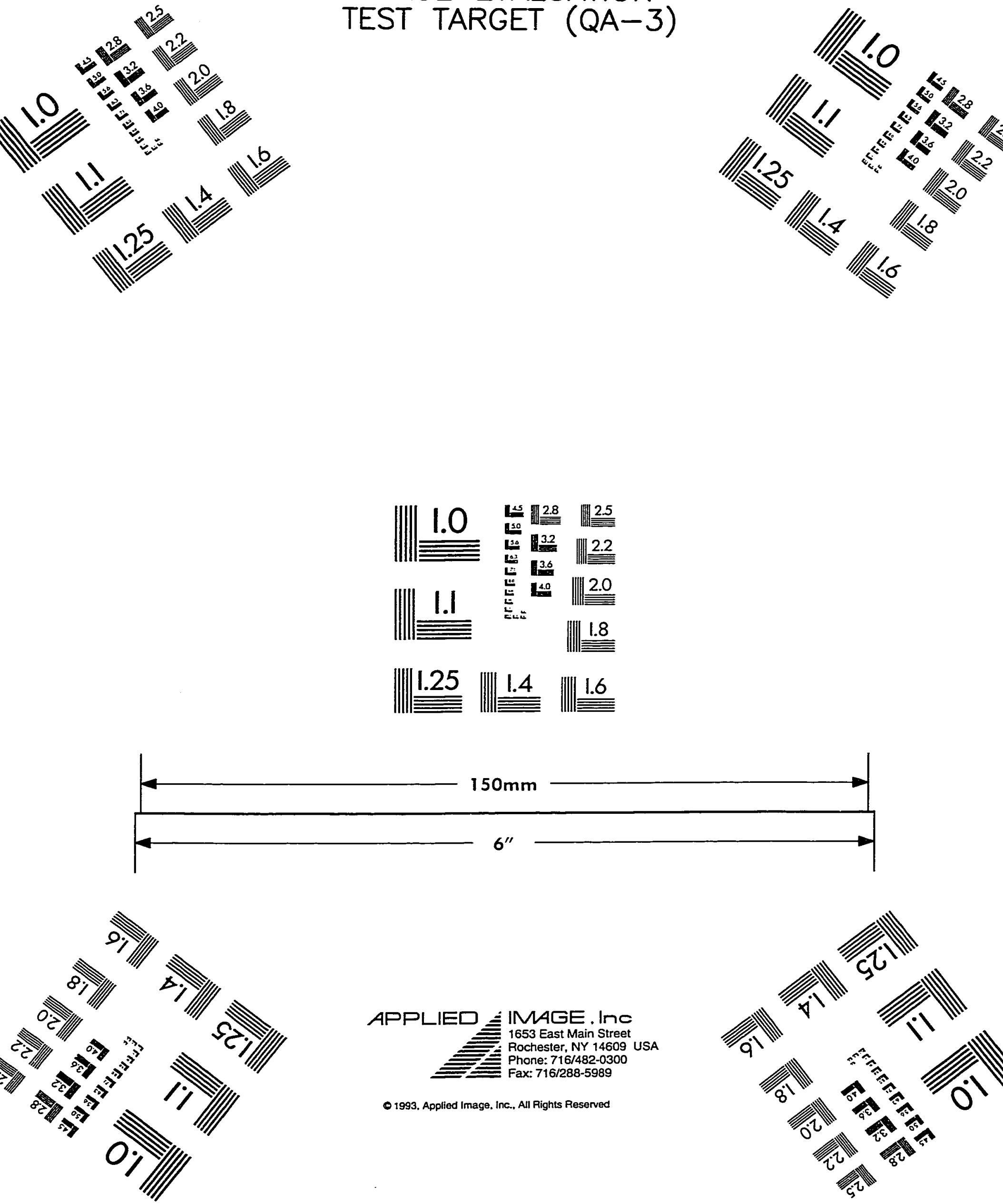

APPLIED ڤIMAGE IINC
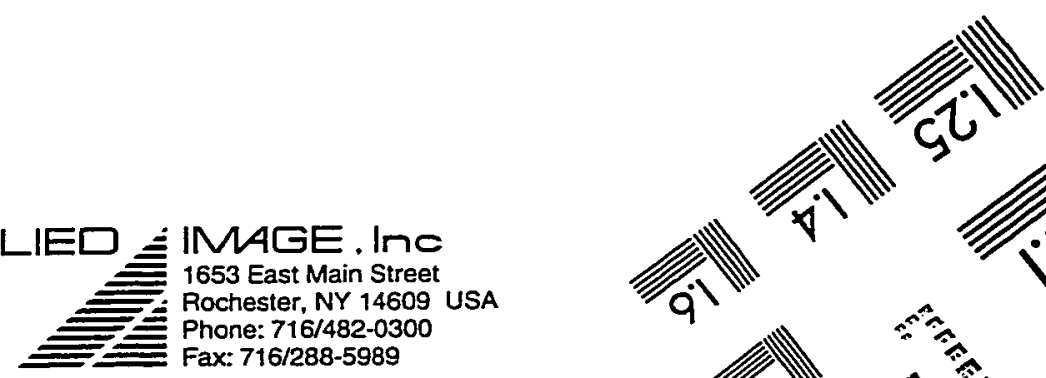